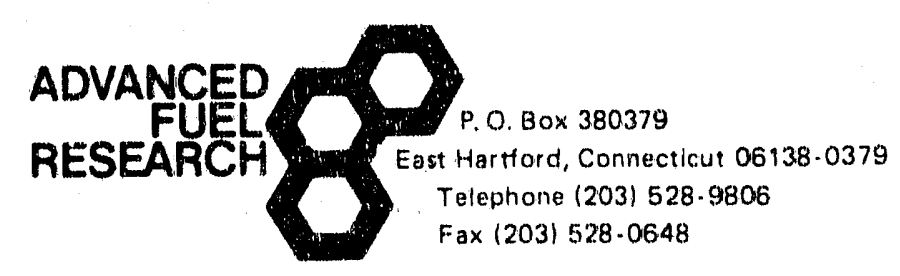

DOE/PC/91026- - T4

4

DES2 018882

\title{
THE DUAL. ROLE OF OXYGEN FUNCTIONS IN COAL PRETREATMENT AND LIQUEFACTION: CROSSLINKING AND CLEAVAGE REACTIONS
}

\author{
First Annual Report \\ \#523085 \\ For the Period \\ April 1, 1991 to March 31, 1992 \\ MICHAEL A. SERIO \\ ERIK KROO \\ HSISHENG TENG \\ SYLVIE CHARPENAY \\ PETER R. SOLOMON \\ with contributions by: \\ RIPUDAMAN MALHOTRA (SRI) \\ DONALD MCMILLEN (SRI)
}

Work Performed Under Contract No. DE-AC22-91-PC91026

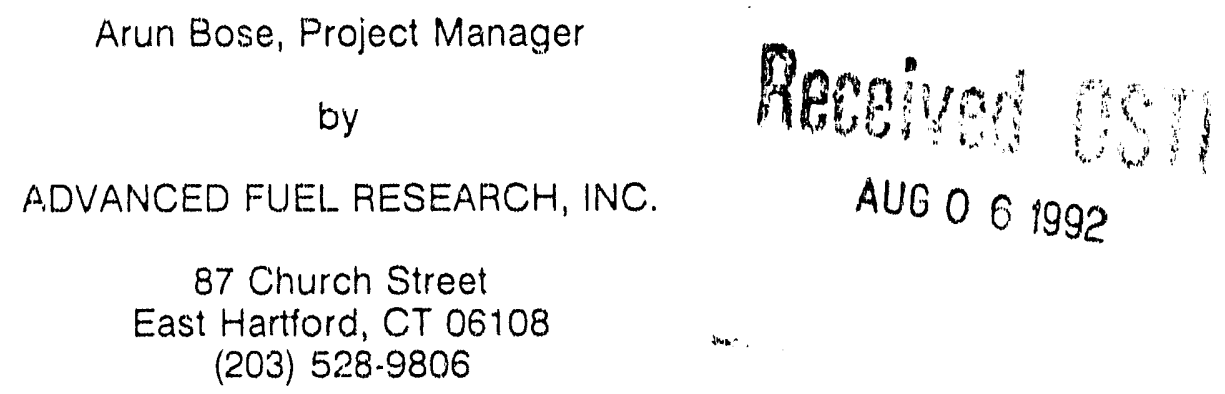

"US/DOE patent clearance is not required prior to the publication of this document."

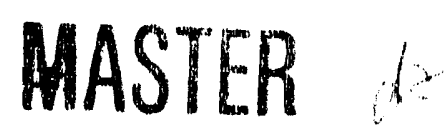

DISTHIBUTIOH OF THIS DUEUMETT IS UNLIMILA

Researc'i, analytical services and consulting for the development of new and improved clean fuels. 
THE DUAL ROLE OF OXYGEN FUNCTIONS IN COAL PRETREATMENT AND LIQUEF:ACTION: CROSSLINKING AND CLEAVAGE REACTIONS

FIRST ANNUAL REPORT - CONTRACT NO. DE-AC22-91-PC91026

\section{TABLE OF CONTENTS}

Disclairner

Abstract ii

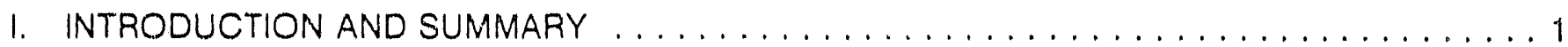

II. TASK 1 - WORK PLAN $\ldots \ldots \ldots \ldots \ldots \ldots \ldots \ldots \ldots \ldots \ldots \ldots \ldots \ldots \ldots \ldots$

III. TASK 2 - STUDIES WITH COALS AND MODIFIED COALS $\ldots \ldots \ldots \ldots \ldots \ldots$

IV. TASK 3 - STUDIES WITH POLYMERIC MODEL SYSTEMS . . . . . . . . . . . . . 21

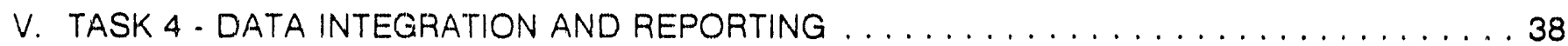

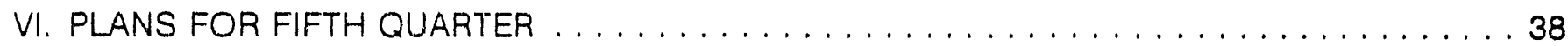

References .................................. 39

\section{DISCLAIMER}

This report was prepared as an account of work sponsored by an agency of the United States This report was prepared as an acoutes Governiment nor any agency thereof, nor any of their employees, makes any warranty, express or implied, of assumes any legal liability or responsibility for the accuracy, completeness, or usefulness of any information, apparatus, product, or process disclosed, or represents that its use would not infringe privately owned rights. Refer. ence herein to any specific commercial product, process, or service by trade name, trademark, ence herein to any sperwise does not necessarily constitute or imply its endorsement, recominendation, or favoring by the United States Government or any agency thereof. The views inendation, or lavoring by the United States Government or any agency thereof. 


\section{DISCLAIMER}

This report was prepared as an account of work sponsored by the United States Government. Neither the United States nor the United States Department of Energy, nor any of their employees, makes any warranty, express or implied, or assumes any legal liability or responsibility for the accuracy, completeness, or usefulness of any information, apparatus, product, or process disclosed, or represents that its use would not infringe privately owned rights. Reference herein to any specific commercial product, process, or service by trade name, mark, manufacturer, or otherwise, does not necessarily constitute or imply its endorsement, recommendation, or favoring by the United States Government or any agency thereof. The views and opinion of authors expressed herein do not necessarily state or reflect those of the United States Government or any agency thereof. 


\section{ABSTRACT}

During the past year, work was done on preparing samples of modified coals and improving the FT.IR methods used to describe these coals. Samples of demineralized coals have now been prepared for both Zap and Wyodak coals. A portion of each sample has been reacted with $1 \mathrm{~N}$ barium solution, which has a $\mathrm{pH}$ value of around 8.2 , in order to ion-exchange the carboxyl groups. A second set of samples was prepared by reaction with a solution of $0.8 \mathrm{~N} \mathrm{BaCl}_{2} / 0.2 \mathrm{~N} \mathrm{Ba}(\mathrm{OH})_{2}$, which has a pH of about 12.7 . According to Schafer, both pherolic and carboxyl groups will be completely exchanged under these conditions. These samples were subjected to characterization by pyrolysis in the TG-FTIR system and liquefaction in a donor solvent. The results show that, for both Wyodak and Zap, demineralization tends to increase the tar yisld and decrease the yields of gas and char. For the Ba exchanged coals, there was a decrease of tar with the extent of ion-exchange with barium and a corresponding increase in the total arnount of gas evolution. When the liquefaction results were examined, it was found that both the liquefaction and tar yields follow the order [demin.] $>$ [demin. $\left.+\mathrm{Ba}^{2+}(\mathrm{pH}=8)\right]>\left[\right.$ demin. $+\mathrm{Ba}^{2+}(\mathrm{pH}=$ 12.6)]. It was also found that for this set of samples, both the relative amounts of pyrolysis $C O$ evolved before $750{ }^{\circ} \mathrm{C}$ and the total pyrolysis $\mathrm{CO}$ were indicators of the extent of retrogressive reactions in pyrolysis and liquefaction.

A procedure for restoring the moisture level of modified coal samples was developed. These moisturized samples were subject to routine liquefaction experiments and pyrolysis analysis in the TG-FTIR. The saturation moisture content of the modified coal samples, for both Zap and Wyodak, increases with the extent of ion-exchange, and varies in the range of 15-25 wt\% a.r. Moisturization reduces the tar yie!d in pyrolysis for the demineralized samples, increases the yield for $\mathrm{pH} 8$ ion-exchanged samples, and has little effect on the yield for $\mathrm{pH} 12.6$ ion-exchanged samples. Pyrolysis char yield, on the other hand, was reduced, for all the modified samples, by increased moisture content. Liquefaction experiments have been done for these samples but the product work up is not yet complete.

An FT.IR method was developed to quantify the concentration of carboxyl groups in coals and modified coals. The preliminary results show the expected increases in $\mathrm{COOH}$ concentration when the coals are acid washed or demineralized and the expected decreases when the coal is calcium loaded. Work also continued on the development of a curve resolving program to analyze the $\mathrm{OH}$ region of the FT-IR spectrum. Some preliminary results are reported. If this data is considered (on a qualitative basis) along with the data supplied on carboxyl group changes, it can be seen that the changes in the free $\mathrm{COOH}$ and the o-dihydroxyl are usually in the same direction for each coal modification. This observation provides evidence that both of these groups can be ion-exchanged in the original coal, which probably is related to their propensity for undergoing retrogressive reactions.

The preparation of polymer mixtures dominated by hexa(phenylene) showed that characterization and functionalization of moderate molecular weight polyphenylenes proves to be very difficult, owing to the insolubility even of these low molecular weight oligomers. On the other hand, the preparation of moderate molecular weight C.C.O polymers $(n=10$ to 30 ) has proven to be easier than we had anticipated, after difficulties with unwanted side reactions were suitably minimized with a phase-transfer catalyst approach. Although these polymers have a labile backbone and do not therefore provide a refractory framework with which to study unencumbered the reactions of carboxylic acid groups we plan to attach to the polymers, these materials will constitute the most coal-related polymer models that have been studied to date. They will, therefore, provide very appropriate surrogates for addressing the retrograde reactions of phenolic and carboxylic acid functions.

The work on decarboxylation and coupling reactions for activated acids from this contract and from the literature was summarized. The following preliminary conclusions were reached: 1) simple benzoic acids (i.e., unsubstituted by anything except carbon) do not rapidly decarboxylate below $400^{\circ} \mathrm{C}$, except in the presence of strong base and or electron transfer agents, and 2) upon decarboxylation, they tend to form rather srraller amounts of coupling products than might have been expected, either with themselves or with aromatics that are part of the solvent system. This is true even when the system contains no $H$-donor component that might be expected to scavenge aryl radical intermediates before they could couple. It is also true even when aromatics such as pyrene or naphthol, which are very good radical acceptors, have been added to the system. These low levels of coupling raise an important question. is coupling associated with decarboxylation as important a part of retrograde reactions in low-rank coals as it has been assumed to be? This question will be addressed by additional experiments with model systems, including the use of electron-transfer agents. 


\section{INTRODUCTION AND SUMMARY}

The overall objective of this project is to elucidate and model the dual role of oxygen functions in thermal pretreatment and liquefaction of low rank coals through the application of analytical techniques and theoretical models. The project will be an integrated study of model polymers representative of coal structures, raw coals of primarily low rank, and selectively modified coals in order to provide specific information relevant to the reactions of real coals. The investigations will include liquefaction experiments in microautoclave reactors along with extensive analysis of intermediate solid, liquid and gaseous products. Attempts will be made to incorporate the results of experiments on the different systems into a liquefaction model.

\section{TASK I - WORK PLAN}

Woik was completed on the project test plan and on the subcontract with SRI Internationai. A copy of the work plan is included as Appendix A of the First Quarterly Report.

A literature review of various demineralization methods was completed. Experimental techniques found in the literature for coal demineralization (Bishop and Ward, 1958) and ion-exchange (Schafer, 1970; Hengel and Walker, 1986) use batch type reacters to carry out the given treatment of coal which necessitates filtering of the coal sample any time the solvent is changed. Based on this review, an apparatus for continuous-flow, controlled-atmosphere demineralization and coritrolled pH ion-exchange of coals and other related materials was designed and constructed. To avoid a possible oxidation of the coal sample, a closed system is used, where instead of stirring the batch reactor contents, a continuous flow of solvent through the sample is used. By utilizing valves, it is possible to change solvents without opening the reactor. The different solvents are held in separate reservoirs which are all equipped with sparge valve systems to deoxygenate the solvents before use (with $\mathrm{N}_{2}$ or $\mathrm{He}$ as needed).

Since one of the demineralization steps uses $50 \% \mathrm{HF}$, all of the valves and tubing in the liquid line are made of teflon. A peristaltic pump is used to set the proper flow rate $(2.50 \mathrm{ml} / \mathrm{min}$.). A diagram of the apparatus is given in Fig. $\|-1$.

The contents of each reservoir is as follows:

1. $50 \% \mathrm{HF}$

2. $6 \mathrm{M} \mathrm{HCL}$

3. Deionized water

4. Metal on $\mathrm{NH}_{4}$ ' salt to be ion exchanged.

5. Basic solution 


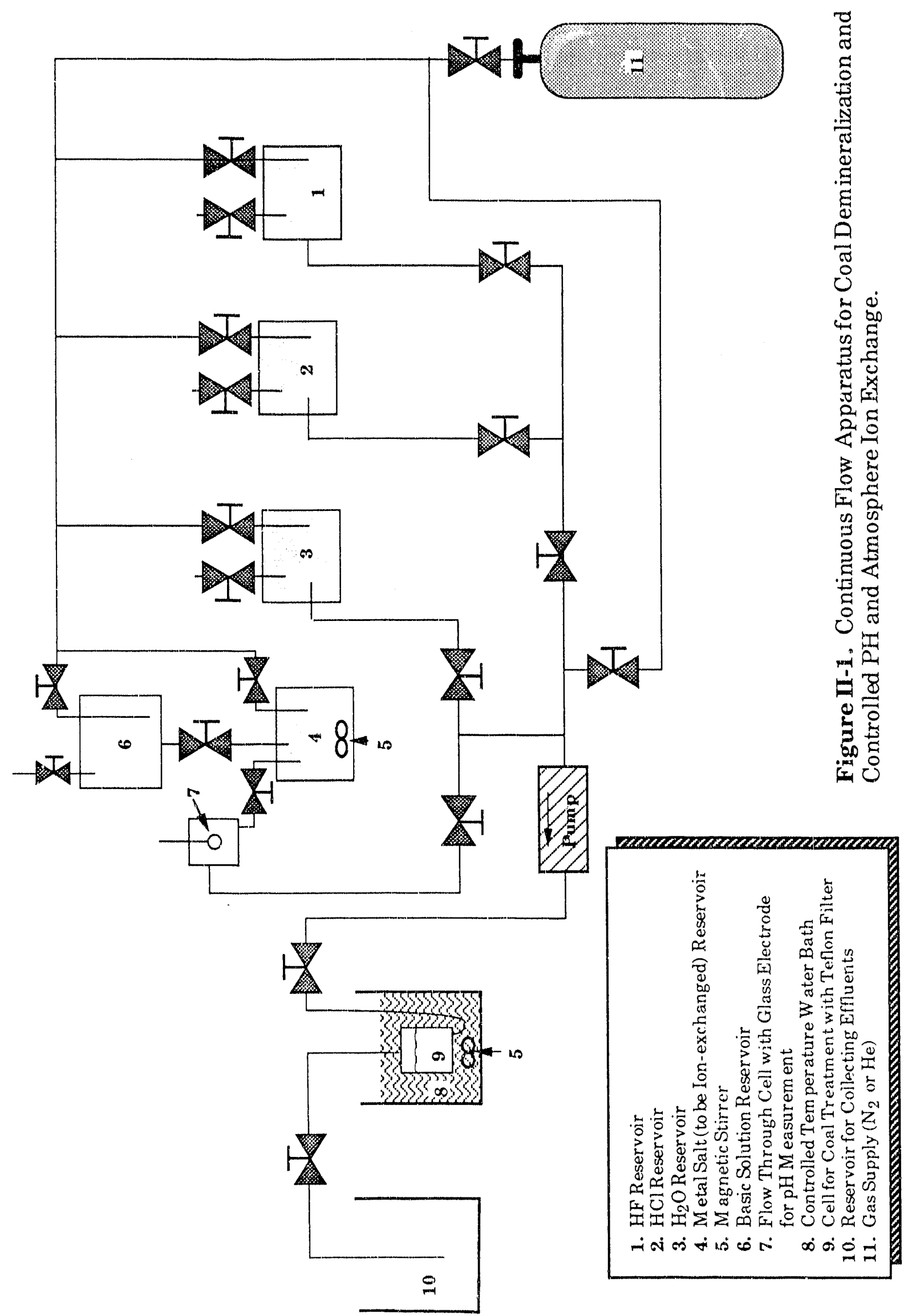


Reservoir 4 is equipped with a magnetic stirrer to set the proper $\mathrm{pH}$ of the ion exchange solvent by addition of a base solution from reservoir 6 . The $\mathrm{pH}$ can be changed continuously and measured via. flow through cell 7 . The sample holder is a telfon filtering cel $(50 \mathrm{ml})$ which is immersed into a water bath thermostat. The system was used to prepare modified coals (Barium exchanged) during the first year.

\section{TASK 2 - STUDIES WITH COALS AND MODIFIED COALS}

During the past quarter, work was done on preparing samples of modified coals and improving the FT-IR methods used to characterize these coals. This work is described below.

\section{A. Preparation of Demineralized and Ion-Exchanged Coal Samples}

\section{Demineralization.}

The procedure is similar to that described in the work of Bishop and Ward (1958). The coal samples used in this study are the Zap and Wyodak coals from the Argonne premium sample bank. The sample sizes are all -100 mesh. Before starting the acid treatment, the samples were thoroughly wetted by mixing with de-ionized water under a nitrogen environment. Demineralization involved washing the coal with a flow of $2 \mathrm{M} \mathrm{HCl}$ for 45 minutes, $50 \% \mathrm{HF}$ for 45 minutes, $2 \mathrm{M} \mathrm{HCl}$ for 45 minutes, and de-ionized water for 120 minutes. The process was performed at $80^{\circ} \mathrm{C}$.

For the first several runs, the sample cell of the demineralization system was not equipped with a mixer, the sample treatment became diffusion limited and the results were not satisfactory. It was found that minerals were not totally removed, and that acids were still retained in the demineralized products since the water-washing was not completely effective. The sample cell was later equipped with a magnetic stirrer, and the demineralization results were much improved. After demineralization, the sample was dried by vacuurn for at least 20 hours at room temperature. The vacuum dried sample was kept in a nitrogen box for analysis and liquefaction.

\section{Ion-Exchange of Carboxyl Groups with Cations $\left(\mathrm{Ba}^{++}\right)$.}

The acidity constant $\left(k_{\mathrm{a}}\right)$ of carboxylic acids is around $10^{-5}$, and that of phenols is around $10^{10}$. Theoretically, almost all carboxyl $\mathrm{OH}$ can be exchanged with cations at $\mathrm{pH} 8$, whereas the phenolic- $\mathrm{OH}$ can remain in acid form, according to the following equation: 


$$
\frac{\left[A^{-}\right]}{[H A]}=\frac{k_{a}}{\left[H^{+}\right]}
$$

where $H A$ is either carboxyl or phenolic group in acid form. At $\mathrm{pH} 8,\left[\mathrm{~A}^{\cdot}\right] /[\mathrm{HA}]$ would be a value of order $10^{3}$ for carboxyl groups, and $10^{2}$ for phenols. Schafer's experimental results also suggest that the carboxyl groups in coal can be completely exchanged with cations at pH around 8-8.5 (Schafer, 1970). $1 \mathrm{~N}$ barium acetate solution, which has a $\mathrm{pH}$ value around 8.2 , was used for ion-exchange with carboxyl groups. Roughly $3 \mathrm{~g}$ of demineralized coal was mixed with $300 \mathrm{ml}$ of $1 \mathrm{~N}$ barium acetate in a cell under a nitrogen environment. After 5 minutes of mixing, the $\mathrm{pH}$ value of the mixture dropped to less than 7.5. The mixture was filtered through a Teflon membrane by increasing the nitrogen pressure, and the mixing cell was refilled with another $300 \mathrm{ml}$ of barium acetate. The $\mathrm{pH}$ value of the solution dropped again after mixing. The filtration and refilling procedure was repeated, usually 15-20 times, until the $\mathrm{pH}$ value of the mixture in the cell reached $8.0 \pm 0.1$ and remained constant with mixing. T

drop of the $\mathrm{pH}$ value was probably due to the release of $\mathrm{H}^{+}$from carboxylic acids in the coal.

The mixture was kept under continuous mixing conditions in a nitrogen environment for at least 20 hours before the acetate solution was purged out, and the cell was refilled with a final $300 \mathrm{ml}$ charge of $1 \mathrm{~N}$ barium acetate. After 10 minutes of mixing, the acetate solution was purged out, and the coal sample was washed with $150-200 \mathrm{ml}$ of de-ionized water. The coal sample was then removed from the cell for vacuum drying, which lasted for at least 20 hours. The sample was kept in a nitrogen box after drying.

\section{Ion-Exchange uf Phenolic and Carboxyl Groups with Cations (Ba ${ }^{++}$).}

According to equation 1 , both phenolic and carboxyl groups can be totally exchanged with cations at $\mathrm{pH}$ around 12.5. Schafer (1970) also reported that the exchange of $-\mathrm{OH}$ groups was complete at $\mathrm{pH}$ 12.6. In this study, a solution, recommended by Schafer, of $0.8 \mathrm{~N} \mathrm{BaCl}_{2}$ and $0.2 \mathrm{~N} \mathrm{Ba}(\mathrm{OH})_{2}$ having a $\mathrm{pH}$ of 12.7 , was used for ion-exchange.

Approximately $3 \mathrm{~g}$ of a demineralized coal sample was stirred with $300 \mathrm{ml}$ of the $\mathrm{pH} 12.7$ solution in a nitrogen environment. After 5 minutes of mixing, the mixture was filtered through a membrane and the cell was refilled with another $300 \mathrm{ml}$ of the $\mathrm{pH} 12.7$ solution. The purging and refilling procedure was repeated 3 times, and the $\mathrm{pH}$ value of the final mixture was around 12.6. The mixture was continuously mixed under a nitrogen environment for at least 20 hours for exchange. After this long-time exchange period, the solution was purged out, and the celi was refilled with the $\mathrm{pH} 12.7$ solution.

After 10 minutes of mixing, the solution was purged out, and the coal sample was washec' with a 
solution of $0.1 \mathrm{~N} \mathrm{BaCl}_{2}$ and $0.03 \mathrm{~N} \mathrm{NaOH}$, which has a pH around 12.7, to avoid hydrolysis of the exchanged coal. The coal sample was then removed from the cell for vacuum drying. After drying, the sample was kept in a nitrogen box for further study.

It was noticed, in the process of ion-exchange that part of the coal structure was dissolved in the high $\mathrm{pH}$ value solution, since the filtrate had a yellowish color. This is most likely due to hydrolysis of the ester linkage in coal, i.e.,

$$
R-O-\stackrel{O}{1}-R^{\prime}+O H^{-} \rightarrow R-O H+-C \stackrel{0}{C}-R^{\prime}
$$

We estimated the amount of coal structures (so called humic acids) dissolved in the high $\mathrm{pH}$ value solutions during complete ion-exchange be about 6.6 wt $\%$ daf of the demineralized Zap and 17 wt $\%$ daf of the demineralized Wyodak. The humic acids from the coal samples were precipitated in acid solutions, and will be suljject to pyrolysis analysis in the TG.FTIR and FT-IR analysis in the form of $\mathrm{KBr}$ pellets.

\section{Results and Discussion}

The results of sample analysis by programmed pyrolysis in the TG-FTIR are shown in Figures III-1 to III-4, and summarized in Table III-1. These results show that, for both Wyodak and Zap, demineralization tends to increase the tar yield, whereas both the gas and char yields were reduced. Table III-1 also shows a decrease of the tar yield with the extent of ion-exchange with barium, and a corresponding increase in the total amount of gas evolution.

The liquefaction results for different samples are shown in Table III-2. Comparing Table III-2 with Table IIII-1, it is found that both liquefaction and tar yields follow the order [demin.] $>$ [demin. $+\mathrm{Ba}^{++}\left(\mathrm{pH}^{+}\right.$ 8)] $>$ [demin. $+\mathrm{Ba}^{\prime}(\mathrm{pH}$ 12.6)]. This result was expected, since having the carboxyl or phenolic groups in the salt form makes it easier to release $\mathrm{CO}_{2}$ and $\mathrm{CO}$, and therefore, to generate free radicals which would result in crosslinking of the coal structure.

For the Wyodak sample, both the tar and liquefaction yields are higher for the fresh sample than for the sample barium exchanged at $\mathrm{pH} 8$. However, in the case of Zap, the fresh sample shows a higher yield of tars but lower yields in liquefaction than the sample exchanged with barium at $\mathrm{pH} 8$. 


\begin{tabular}{|c|c|c|c|c|c|c|c|c|c|c|}
\hline \multirow[b]{3}{*}{$\begin{array}{c}\text { Coal } \\
\text { (Type/Preparation) }\end{array}$} & \multicolumn{10}{|c|}{ Results of Pyrolysis Experiments with Coals and Modified Coals } \\
\hline & \multicolumn{4}{|c|}{ Proximate Analysis (wt.\%), as rec.) } & \multicolumn{6}{|c|}{ Pyrolysis Products (wt.\%, daf) } \\
\hline & Ash & Moisture & Fixed C & Volatile & Char & Tars & $\mathrm{CO}_{2}$ & $\mathrm{CO}$ & $\mathrm{H}_{2} \mathrm{O}$ & $\mathrm{CH}_{4}$ \\
\hline \multicolumn{11}{|l|}{ Zap Lignite } \\
\hline fresh & 10.3 & 22.5 & 38.9 & 28.3 & 57.1 & 7.3 & 8.9 & 14.7 & 14.3 & 2.2 \\
\hline demin. & 1.5 & 3.5 & 50.8 & 44.2 & 53.5 & 20.1 & 4.84 & 10.4 & 8.4 & 2.73 \\
\hline demin. $+\mathrm{Ba}^{++}(\mathrm{pH}=8)$ & 15.4 & 5.1 & 43.8 & 35.7 & 55.1 & 5.53 & 11.7 & 15.8 & 18.6 & 2.55 \\
\hline $\begin{array}{l}\text { demin. }+\mathrm{Ba}^{++} \\
(\mathrm{pH}=12.6) \\
\end{array}$ & 37.8 & 9.0 & 27.6 & 25.6 & 51.9 & 2.87 & 10.5 & 24.1 & 15.5 & 2.56 \\
\hline \multicolumn{11}{|l|}{ Wyodak } \\
\hline fresh & 13.8 & 22.5 & 36.8 & 26.9 & 57.8 & 15.7 & 7.15 & 15.7 & 13.3 & 3.3 \\
\hline demin. $+\mathrm{H}^{*}$ & 6.0 & 4.0 & 4.6 & 4.4 & 51.1 & 25.4 & 4.0 & 11.2 & 7.0 & 3.1 \\
\hline demin. & $\underline{0}$ & 2.2 & 49.2 & 48.6 & 50.3 & 29.7 & 2.45 & 9.58 & 4.69 & 2.82 \\
\hline demir. $+B a \cdots(p h=8)$ & 14.9 & 4.4 & 43.5 & 37.2 & 53.9 & 13.6 & 8.80 & 13.6 & 12.4 & 2.85 \\
\hline $\begin{array}{l}\text { demin. }+\mathrm{Ba} \cdot \\
(\mathrm{ph}=12.6)\end{array}$ & 36.2 & 6.0 & 29.7 & 28.1 & 51.4 & 12.8 & 6.42 & 19.6 & 10.6 & 2.92 \\
\hline
\end{tabular}

It can be seen that the demineralized Wyodak containing $\mathrm{H}^{+}$, which was due to incomplete washing after acid treatments, shows a low liquefaction yield, although the tar yield in pyrolysis is high. Since the retrograde reactions during coal pyrolysis or liquefaction appear to be in part due to the crosslinking between carboxyl and/or hydroxyl functions, it is possible that the $\mathrm{H}^{*}$ retained in the demineralized coal catalyzes the retrograde reactions by the following mechanism:<smiles></smiles>

$\oplus$

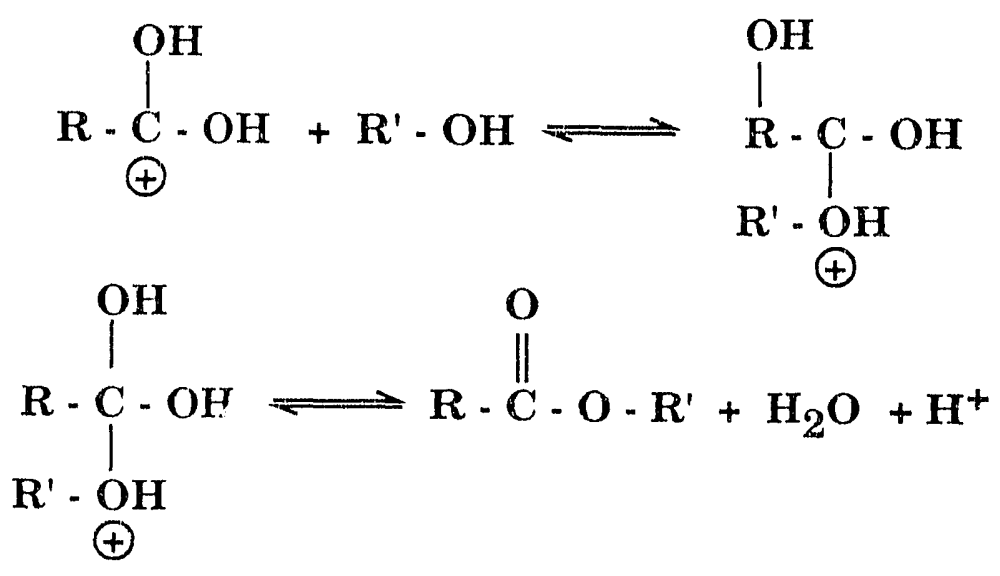


The catalytic effect of $\mathrm{H}^{+}$is shown to be more prominent in the liquid phase, since the liquefaction yield was depressed for the acid-contaminated sample, whereas the tar yield in pyrolysis was still high. This result indicates that excess acid should be avoided in order to obtain high liquefaction yields.

It is of interest to note that barium exchange at $\mathrm{pH} 8$ does not reduce the oil yield in liquefaction for demineralized samples for both Zap and Wyodak. Since only carboxyl groups were exchanged at $\mathrm{pH}$ 8 , it is suggested that oil molecules, which have smaller molecular weights than asphaltenes, contain more phenolic $\mathrm{OH}$ groups than carboxyl groups. Table III-2 also shows that barium exchange at $\mathrm{pH}$ 12.6, where both carboxyl and phenolic $\mathrm{OH}$ were exchanged into salt forms, significantly reduced both oil and asphaltene yields in liquefaction.

It is also of interest to note that the gas yields of liquefaction and pyrolysis do not always follow the same trend. Table III-1 shows that, in pyrolysis, the total yield of oxygen-containing gases (i.e., $\mathrm{CO}_{2}$, $\mathrm{CO}$, and $\mathrm{H}_{2} \mathrm{O}$ ) always increases with decreasing tar yield. Table III-2 shows the expected increase of the liquefaction yields with tar yield. However, the gas yields in liquefaction show an irregular variation. For example, the $\mathrm{CO}_{2}$ yield is high for the partially barium exchanged Zap lignite, and is significantly reduced for the completely barium exchanged sample. The Wyodak subbituminous coal shows the opposite trend. For the ion-exchanged Zap lignite, the decrease of the $\mathrm{CO}_{2}$ yield in liquefaction can be explained by the loss of some organic components, which contain $\mathrm{CO}_{2}$-forming functions, during barium exchange at high $\mathrm{pH}$. However, the behavior shown for the Wyodak coal is not able to be explained at this time.

Several aspects if the data revealed in Figs. III-1 to $111-4$ merit further comment. For samples which contain acidic functions in the salt form, including fresh and barium exchanged samples, there is always a water evolution peak present at around $200{ }^{\circ} \mathrm{C}$. This $200{ }^{\circ} \mathrm{C}$ peak is obscure for demineralized samples. It is very likely that this peak is due to thi evolution of moisture which was ionically bonded on the salt structure. For vacuurn dried samples, it can be seen that the moisture content always increases with the amount of barium in the samples. This indicates that the acidic functions in the salt forms attract polar water molecules. These attracted water molecules cannot be removed by vacuum drying, but only by raising the temperature of the sample. 
Nelght \%
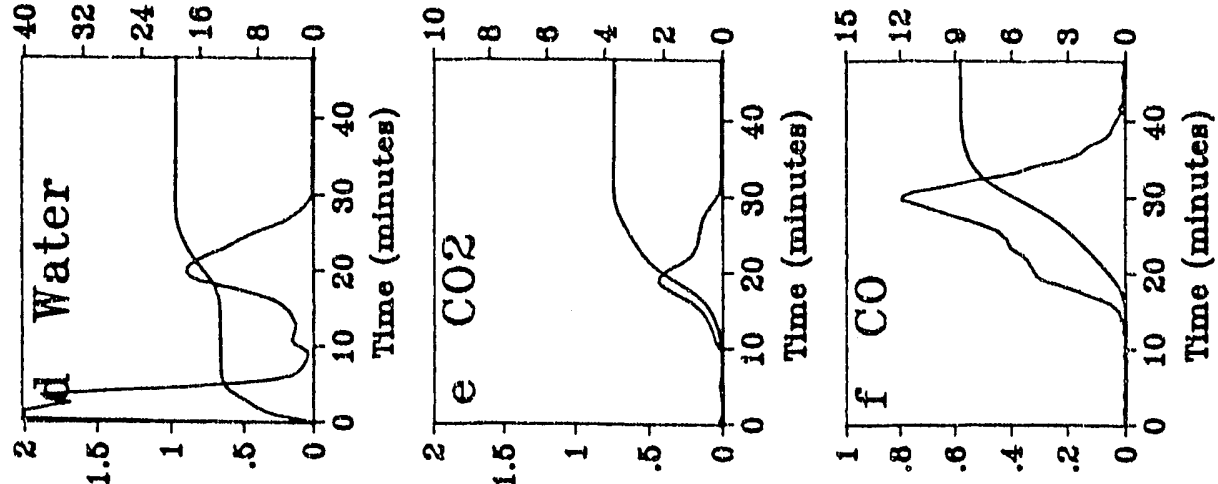

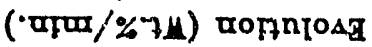

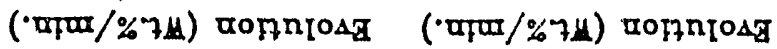

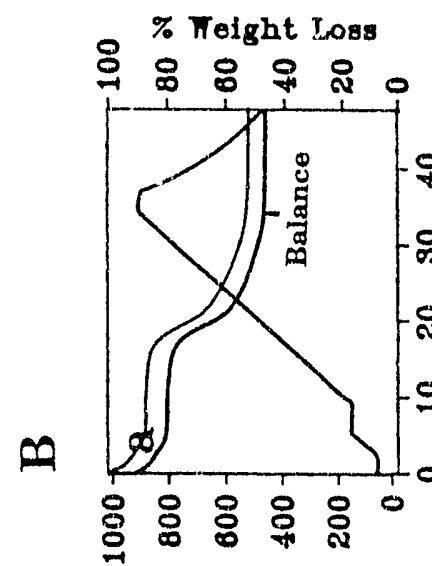

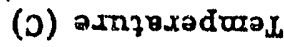

Felght \%

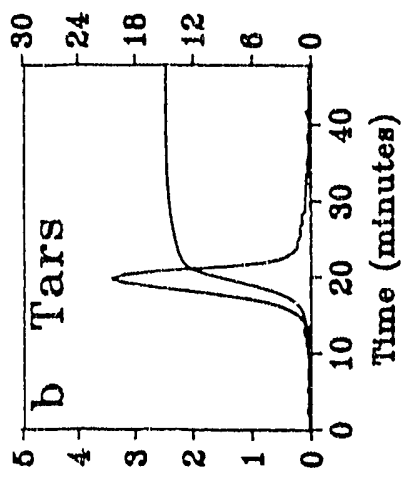

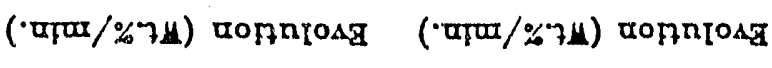

Felght \%

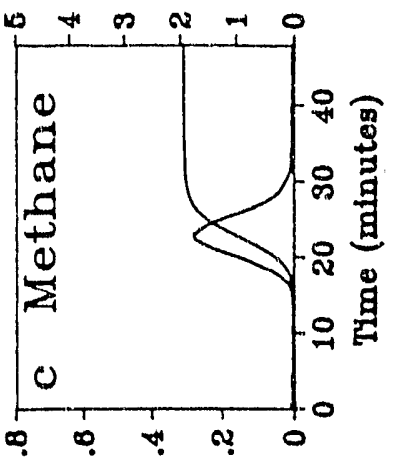

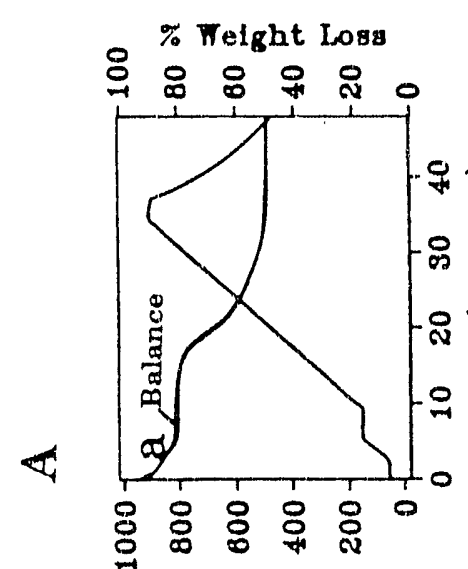

(a) จxnfвsoduxas
Welght \%

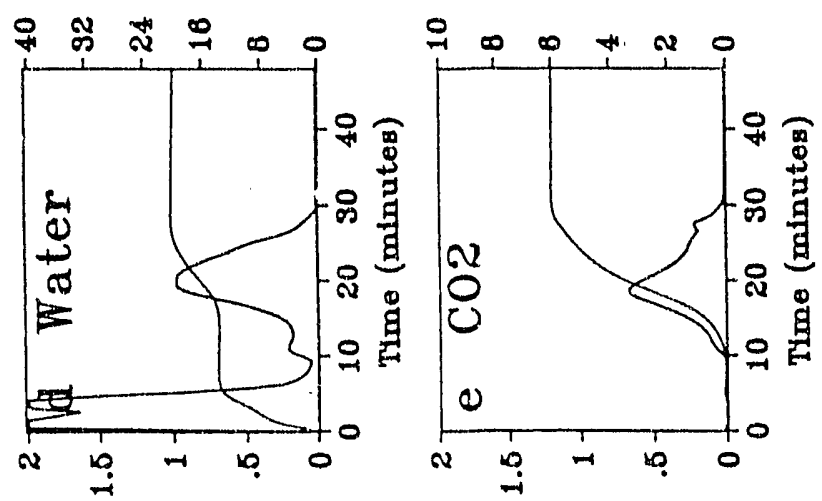

Nolght \%
Feight \%

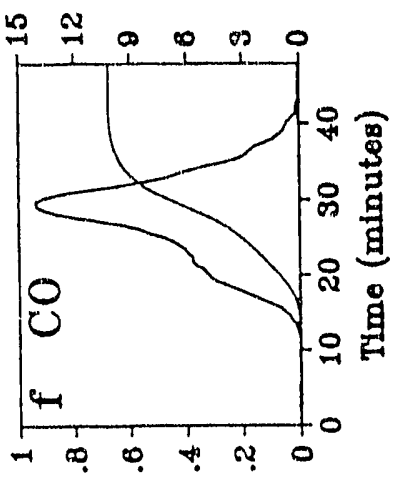

Height \% 
Netght $\%$

Helght :

Melght:

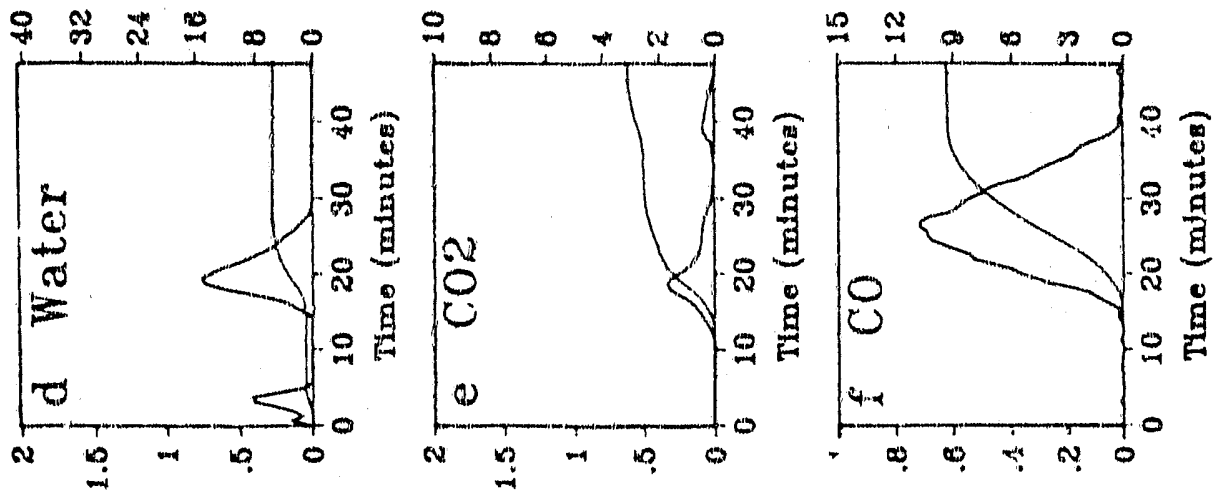

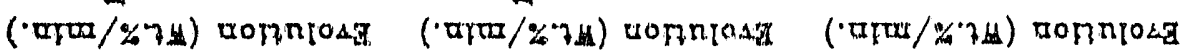

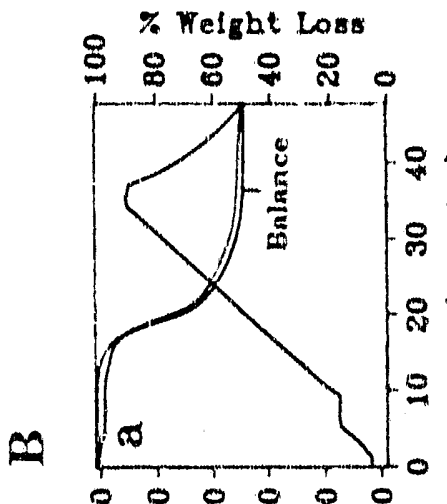

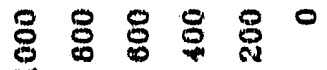

(D) asmpgradtorad

Telght $\%$

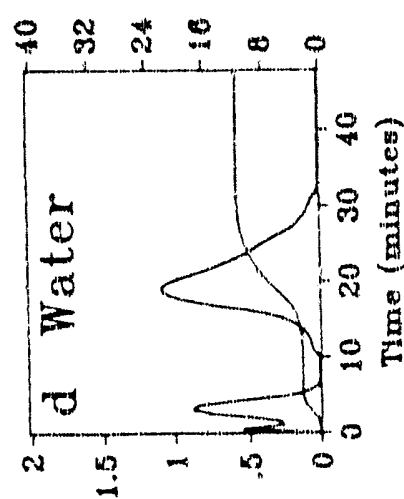

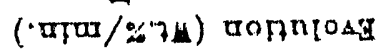

(ว) a.m7
Nelght $\%$

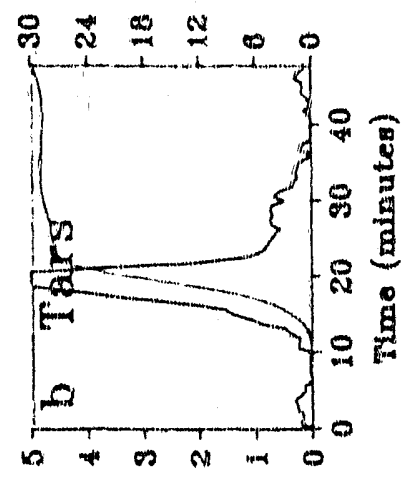

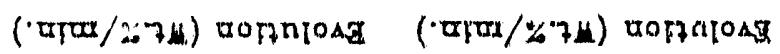

Netght \%

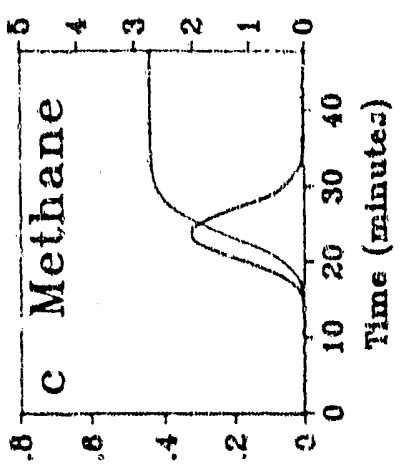

Neight $\%$

Teight $\%$
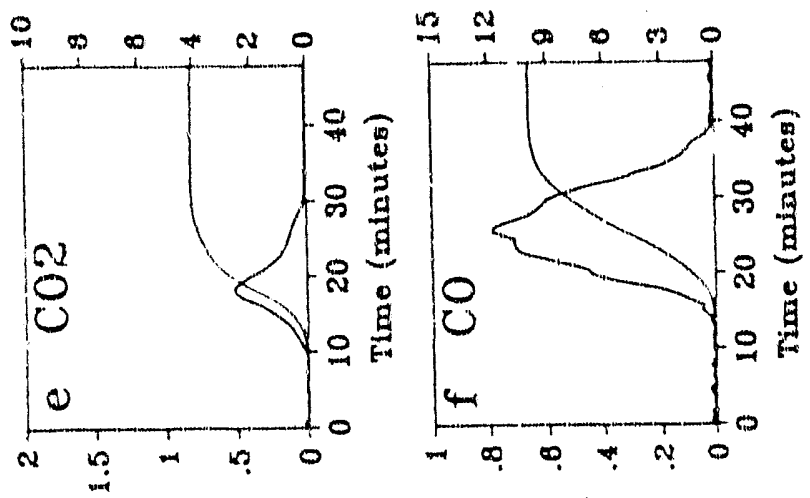

$(\cdot$ тाx $/ \% 74)$ gomnios
\% Weight Loss

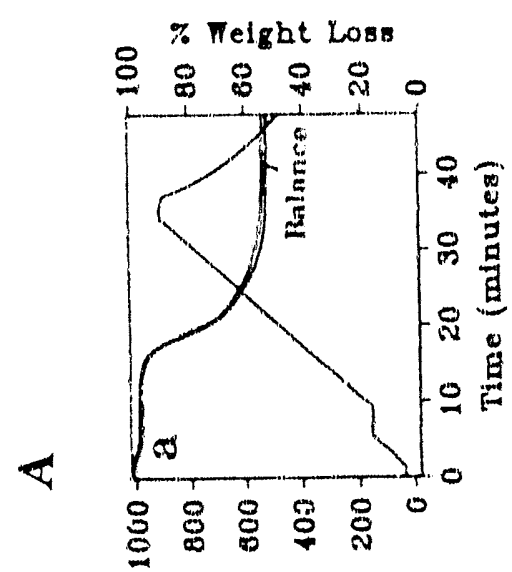

Nelght $\%$

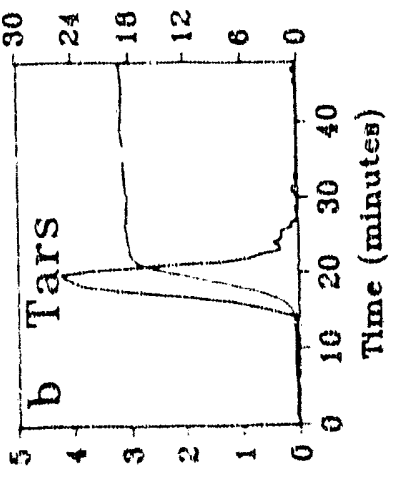

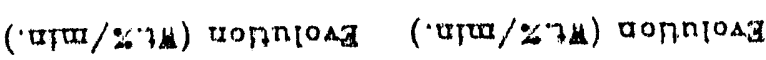


Noight $\%$

Nolght $\pi$

Toight $\%$
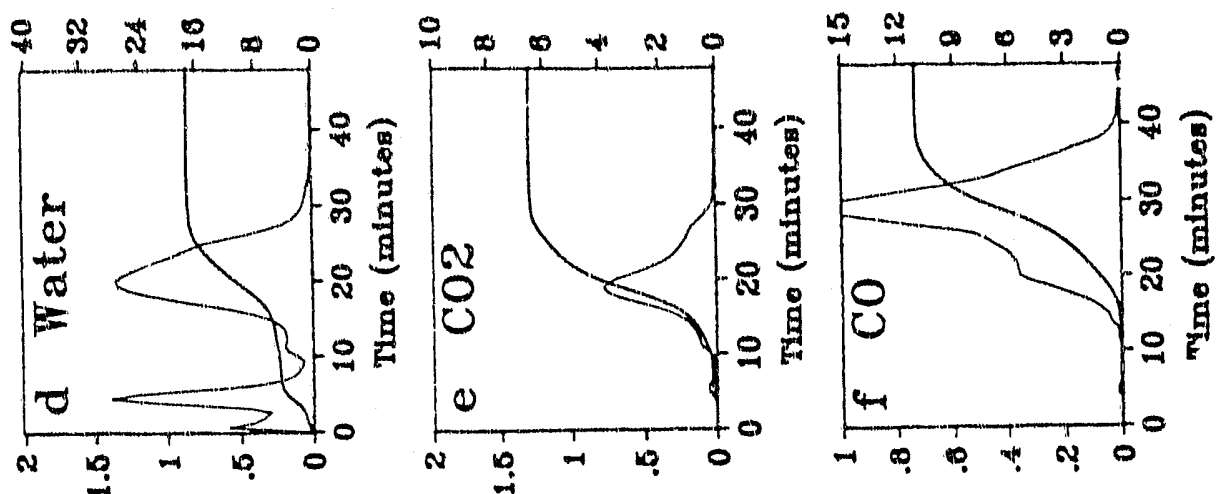

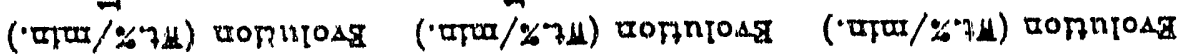

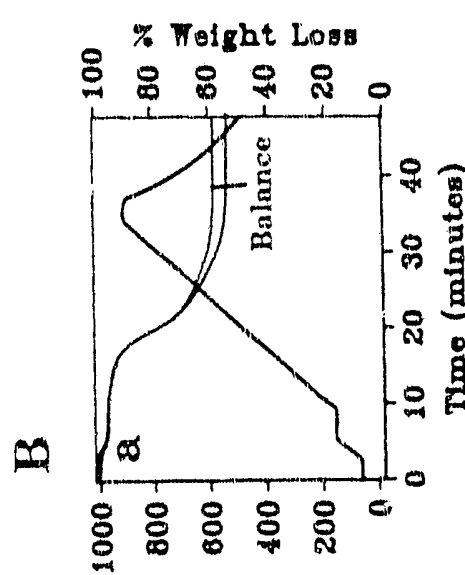

(ग) oxngadurad
Toight $\%$

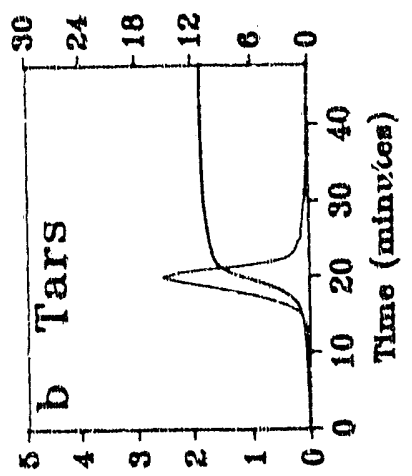

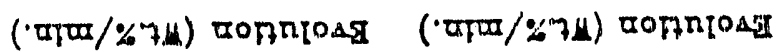

Foight \%

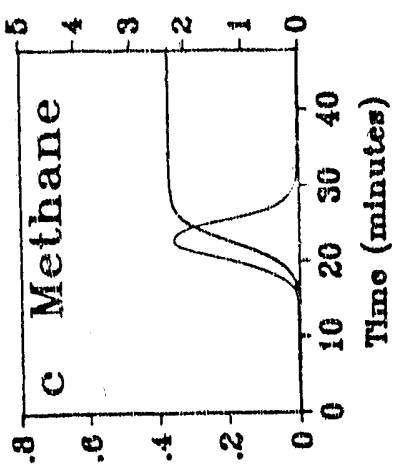

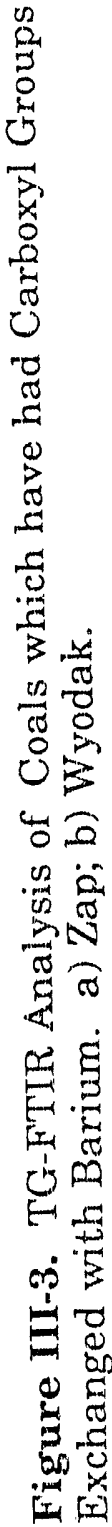

Tight \%

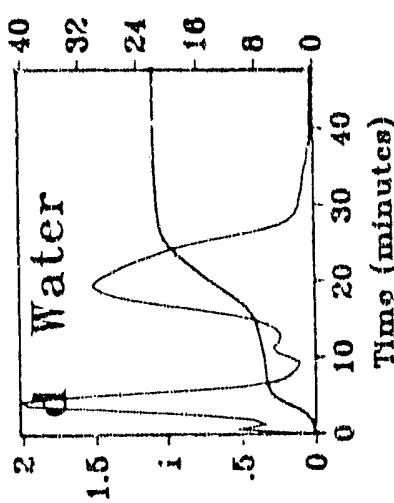

Felght \%

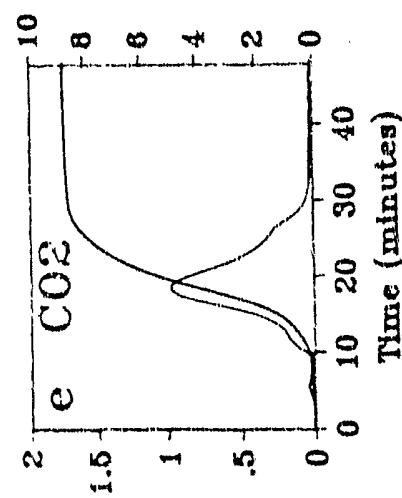

Fielaht \%

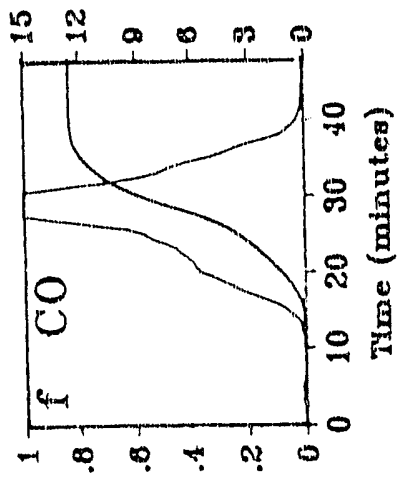

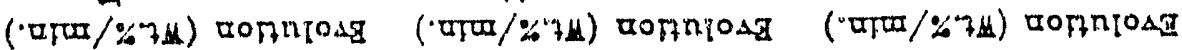

Weight \%

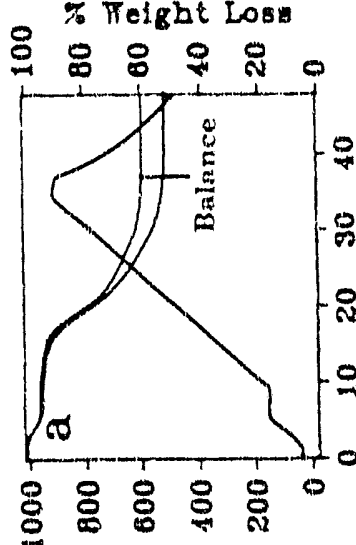

(0) อxmpuxodurad
Neight \%

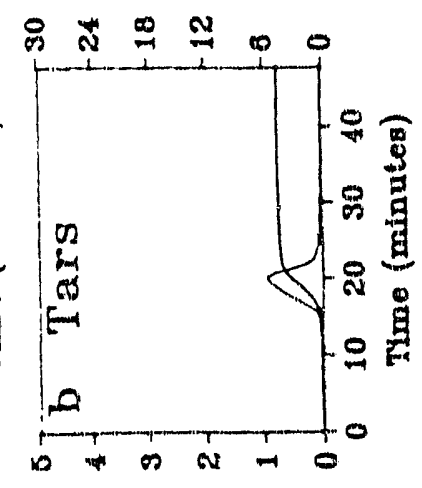

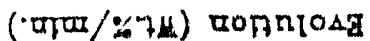

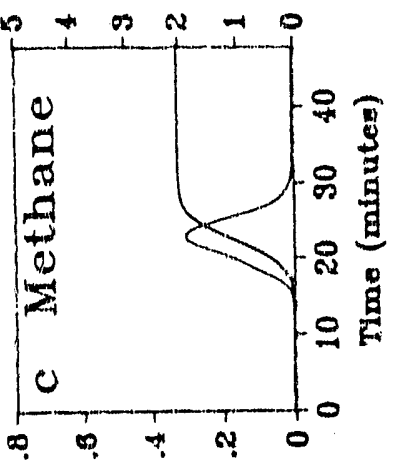

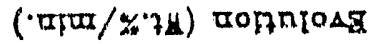




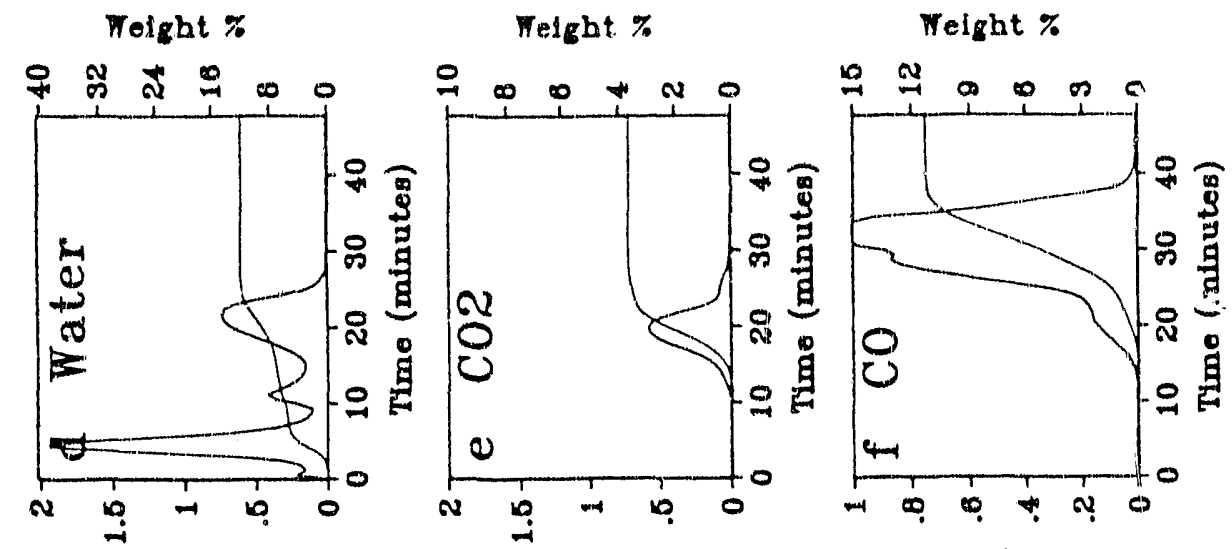

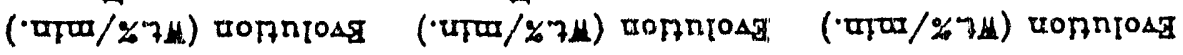

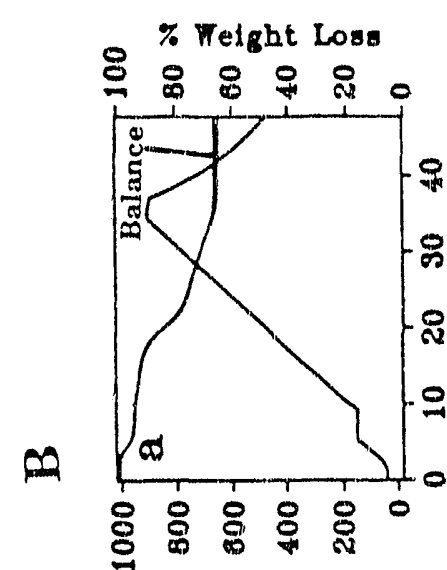

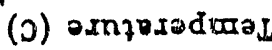

Telght \%

Felpht \%

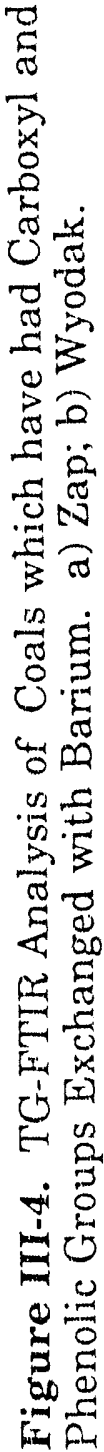

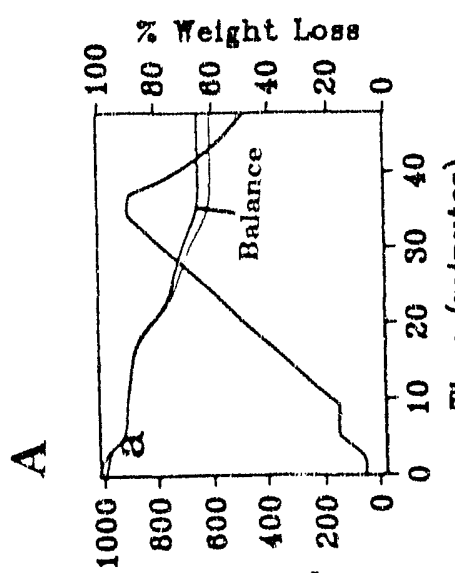

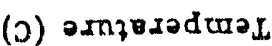

Weight \%

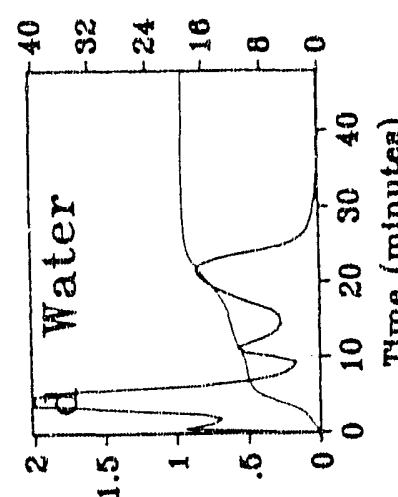

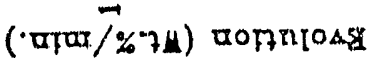

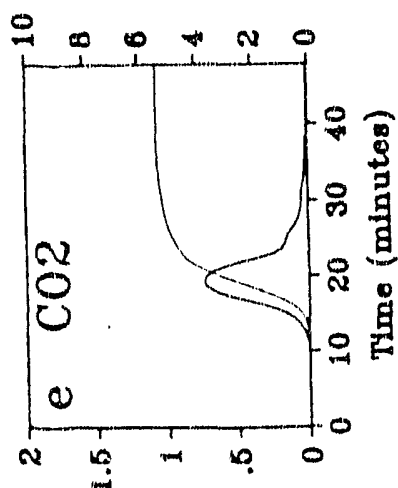

("पrow/2\%74) ronnjost

Neight \%

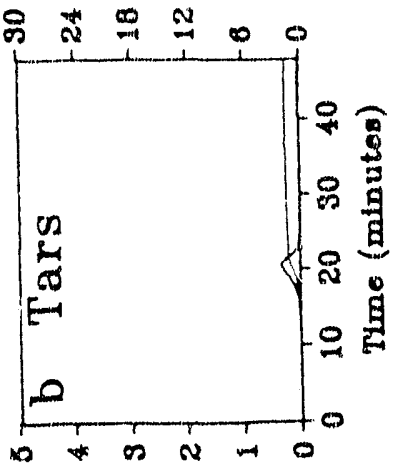

( $\mathrm{arm} / 274$ ) donnjost
Felght \%

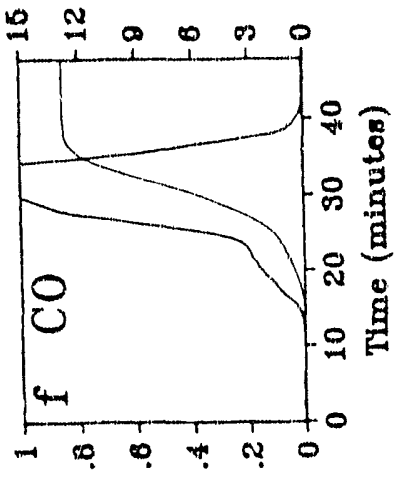

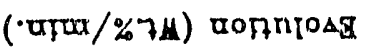

Weight \%

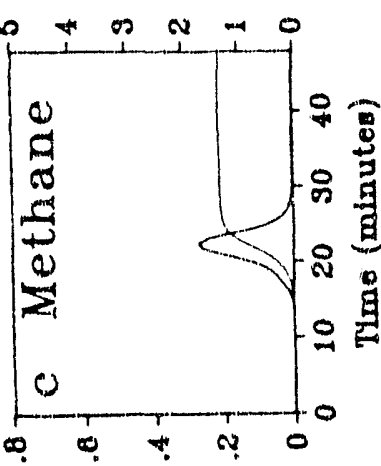

(" 


\begin{tabular}{|c|c|c|c|c|c|c|c|c|c|c|}
\hline \multicolumn{11}{|c|}{$\begin{array}{c}\text { TABLE III-2 - Product Yields from Liquefaction Experiments with Coals and } \\
\text { Modified Coals in DHP }\end{array}$} \\
\hline \multirow[b]{2}{*}{$\begin{array}{l}\text { Coal } \\
\text { (Type/Preparation) }\end{array}$} & \multicolumn{2}{|c|}{ Toluene Solubies } & \multirow{2}{*}{$\begin{array}{l}\text { Toluene } \\
\text { Insolubles }\end{array}$} & \multicolumn{7}{|c|}{ Gas } \\
\hline & Total & Oils & & Total & $\mathrm{H}_{2} \mathrm{O}$ & $\mathrm{CO}_{2}$ & co & $\mathrm{CH}_{4}$ & $\mathrm{C}_{2} \mathrm{H}_{\mathrm{B}}$ & $\mathrm{C}_{2} \mathrm{H}_{4}$ \\
\hline \multicolumn{11}{|l|}{ Zap Lignite } \\
\hline fresh. & 26 & 12 & 69 & 5.0 & $\ldots$ & 4.3 & 0.24 & 0.25 & 0.21 & 0.03 \\
\hline demir. & 52 & 26 & 46 & 2.2 & 0.019 & 1.1 & 0.43 & 0.27 & 0.29 & 0.05 \\
\hline demin. $+\mathrm{Ba}^{\prime} \cdot(\mathrm{pH}=8)$ & 37 & 25 & 55 & 8.2 & 0.018 & 7.3 & 0.40 & 0.20 & 0.24 & $\ldots$ \\
\hline $\begin{array}{l}\text { demin. }+B a \cdot \\
(p H:=12.6)\end{array}$ & 15 & 15 & 84 & 1.0 & $\cdots$ & 0.3 & 0.27 & 0.023 & 0.41 & $\cdots$ \\
\hline \multicolumn{11}{|l|}{ Wyodak } \\
\hline fresh' & 39 & 13 & 56 & 5.2 & 0.021 & 4.1 & 0.34 & 0.31 & 0.36 & 0.08 \\
\hline demm $+H^{\circ}$ & 36 & 14 & 64 & 0.36 & 0.017 & $\ldots$ & 0.19 & 0.041 & 0.11 & 0.01 \\
\hline demin. & 54 & 22 & 43 & 2.9 & 0.013 & 2.2 & 0.31 & 0.11 & 0.24 & 0.04 \\
\hline demm $+\mathrm{Ba} \cdots(p h=8)$ & 37 & 25 & 62 & 0.70 & 0.015 & $\ldots$ & 0.43 & 0.076 & 0.19 & $\cdots$ \\
\hline $\begin{array}{l}\text { demin. }+B d^{*} \\
(p h=12.6)\end{array}$ & 7 & 5 & 89 & 3.9 & 0.090 & 3.4 & 0.23 & 0.023 & 0.12 & 0.04 \\
\hline
\end{tabular}

* Data from Serio et al. (1991).

For CO evolution i pyrolysis, the demineralized samples show the major evolution at temperatures between 400 and $800^{\circ} \mathrm{C}$. CO evolution also occurs in a similar temperature range for fresh and ionexchanged samples. However, the evolution is depressed at temperatures lower than about $750^{\circ} \mathrm{C}$, but elevated above this temperature by comparing with that of the demineralized samples. It was also noted that the fraction of $\mathrm{CO}$ evolving before $750^{\circ} \mathrm{C}$ increases with increasing tar yield, as shown in Fig. III-5. This observation is significant. The higher $\mathrm{CO}$ evolution at temperatures lower than $750{ }^{\circ} \mathrm{C}$ for demineralized samples is probably due to more oxygen functions evolving as $\mathrm{CO}$ without crosslinking. For ion-exchanged samples, the depressed $\mathrm{CO}$ evolution at lower temperatures is probably caused by oxygen retention through crosslinking between oxygen functions, and the $\mathrm{CO}$ evolved at $750{ }^{\circ} \mathrm{C}$ or above, is likely from the decomposition of the crosslinking reaction products, which include ether, carbonyl and es.er linkages, in the condensed char structure. The correlation of the total co evolution in coal pyrolysis with pyrolytic tar and liquetaction yields was studied, as shown in Fig. III-E. The data shows that both tar and liquefaction yields increase with decreasing total (pyrolysis) CO yield. Therefore, both the relative amount of $\mathrm{CO}$ evolved before $750^{\circ} \mathrm{C}$ and the totai $\mathrm{CO}$ evolution are indicators of the extent of crosslinking. 

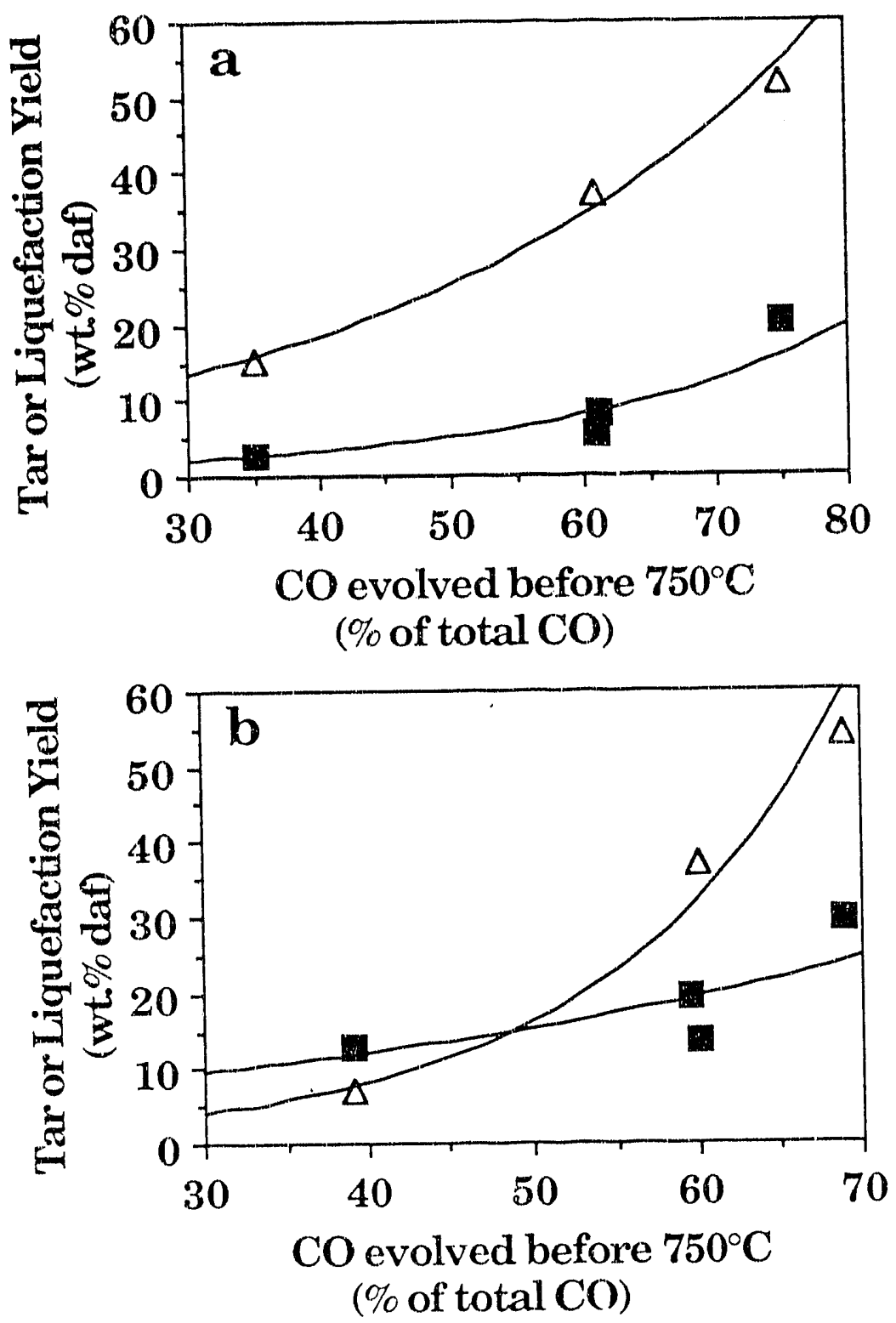

Figure III-5. Correlation of Pyrolysis Tar Yield ( ) and Toluene Solubles from Liquefaction $(\triangle)$ with Pyrolysis $C O$ Evolution Before $750^{\circ} \mathrm{C}$. a) Zap; b) Wyodak. 

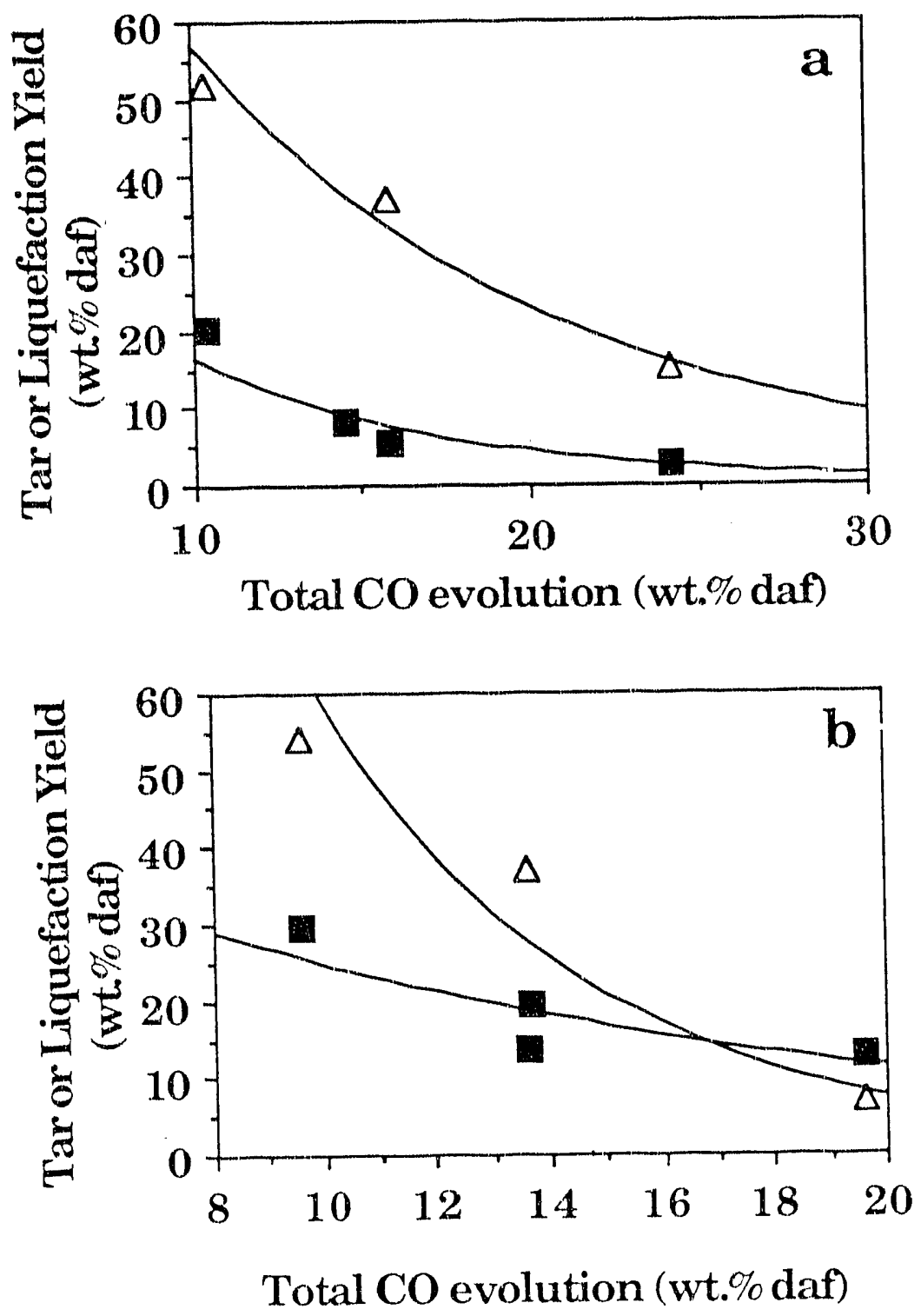

Figure III-6. Correlation of Pyrolysis Tar Yield ( $)$ and Toluene Solubles from Liquefaction $(\triangle)$ with Total Pyrolysis CO Evolution. a) Zap; b) Wyodak. 
The $\mathrm{CO}_{2}$ evolution curve does not show any shape variation due to the change of cation content. However, the yield is basically a decreasing function of tar yield. This has been explained by the mechanism that elimination of $\mathrm{CO}_{2}$ would create aryl radicals to enhance crosslinking.

Figures $I I-1$ to $I I-4$ also show that $\mathrm{CO}_{2}, \mathrm{H}_{2} \mathrm{O}$, and low temperature $\mathrm{CO}$ evolve in a similar temperature range. This might imply that these products are derived from a consecutive mechanism. Stoichiometrically, the following mechanism is a possible one:

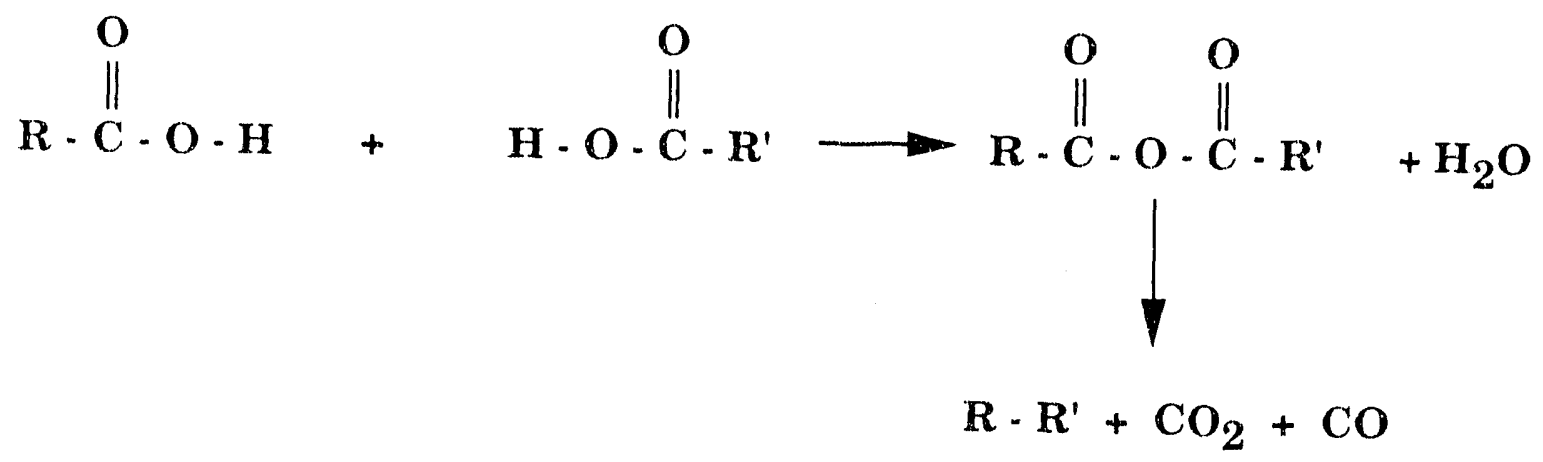

The $\mathrm{CH}_{4}$ yield remains nearly constant for the different samples, and the shapes of the evolution curves are similar. Its value is $2.51 \pm 0.2 \mathrm{wt} . \%$ daf for Zap lignite, and $3.0 \pm 0.3 \mathrm{wt} . \%$ daf for Wyodak.

In theory, all of the carboxyl groups of demineralized samples can be exchanged with barium at $\mathrm{pH} 8$. Consequently, it follows that one could determine the concentration of carboxyl groups in coal by knowing the amount of barium ion exchanged at $\mathrm{pH} 8$. The chemical composition of ash formed by combustion of the barium exchanged sample is predominantly $\mathrm{BaO}$. Therefore, from the ash content of the samples ion-exchanged at $\mathrm{pH} 8$, one can estimate the concentration of carboxyl groups in the coal. Similarly, the total concentration of carboxyl and phenolic groups can be determined by the ash content of the sample ion-exchanged at pH 12.6. The concentration of phenolic groups can be obtained from the difference of the above two measurements. The concentrations of carboxyl and phenolic groups determined in this manner for Zap and Wyodak are shown in Table III-3. The results shown in Table III-3 are similar to those determined by Schafer $(1970,1972)$ for Australian low-rank coals, using barium titration methods. It can be questioned as to whether all of these groups can be exchanged because of steric problems and if the cations could interact with additional sites in the coal. Eventually, we plan to have quantitative measurements from FT-IR methods for comparison (see below). 


\section{Table III-3 - THE CARBOXYL AND PHENOLIC CONTENTS OF ZAP AND WYODAK (meg $\mathrm{g}^{-1}$ dry and ash free basis)}

\begin{tabular}{|l|c|c|c|}
\hline & Carboxyl Group & Phenolic Group & Total Acidity \\
\hline Zap Lignite & 2.52 & 6.74 & 9.26 \\
\hline Wyodak Subbit & 2.40 & 5.76 & 8.16 \\
\hline
\end{tabular}

\section{B. Preparation of Moisturized Coal Samples}

A procedure for restoring the moisture level of modified coal samples was developed. The moisturized samples were prepared by enclosing the vac-dry modified samples in a box with a nitrogen purge of $100 \%$ humidity. The sample exposure to moisture was performed for several days ( 6 days) until no further moisture uptake was observed. These moistured samples were subject to routine liquefaction experiments and pyrolysis analysis in the TG.FTIR.

Pyrolysis of the moisturized coal samples was performed and the data were analyzed. The saturation moisture content of the modified coal samples, for both Zap and Wyodak, increases with the extent of ion-exchange, and varies in the range of $15-25$ wt\% a.r.. The pyrolysis results indicate that the coal structure varies with the moisture content. Moisturization reduces the tar yield in pyrolysis for the demineralized samples, increases the yield for $\mathrm{pH} 8$ ion exchanged samples, and has little effect on the yield for $\mathrm{pH} 12.6$ ion-exchanged samples. Pyrolysis char yield, on the other hand, was reduced, for all the modified samples, by increased moisture content.

The gas evolution during pyrolysis was also influenced by the moisture content. For example, a significant amount of $\mathrm{CO}$ was evolved at temperatures around $850^{\circ} \mathrm{C}$ for the moisturized samples, but this was not observed for the vac-dry samples. It is also of interest to note, only in the case of the demineralized samples, that there was much more CO product in the TG-FTIR char combustion cycle for the moisturized than the vac-dry. This implies that the form of the mineral matter, which acts as a combustion catalyst, is cifferent.

The effect of the moisture content on the mineral matter could also be important in the liquefaction behavior. Liquefaction experiments have been done for these samples but the product work up is not yet complete.

\section{FT-IR Methods for Carboxyl and Phenolic Group Determinations}

An FT-IR method was developed to quantify the concentration of carboxyl groups in coals and modified 
coals which is based on the work of Starinsic et al. (1984). Some preliminary data are shown in Table III-4. These are not yet quantitative since we have used a literature value of the extinction coefficient which will be different for our instrument. However, the relative changes with the various coal modifications can be compared. The results show the expected increases in $\mathrm{COOH}$ concentration when the coals are acid washed or demineralized and the expected decreases when the coal is calcium loaded.

TABLE III-4

\section{PRELIMINARY DATA ON DETERMINATION OF CARBOXYL. FUNCTIONALITIES USING FT-IR METHOD}

\begin{tabular}{|l|l|l|l||}
\hline Coal Type & Treatment & Wavenumber $\left(\mathrm{cm}^{-1}\right)$ & DAF \% COO(H) $\mathbf{X ~ k}_{\mathrm{n}}{ }^{*}$ \\
\hline Zap & $\cdots$ & 1702 & 6.47 \\
\hline & $\mathrm{HCl}$ wash & 1702 & 7.00 \\
\hline & $\mathrm{Ca}^{2+}$ load & 1704 & 2.02 \\
\hline Demin. Zap & $\ldots$ & & \\
\hline & $\mathrm{Ca}^{2+}$ load & 1710 & 10.99 \\
\hline & $\begin{array}{l}\text { Ca load } \\
\text { HCl wash }\end{array}$ & 1702 & 2.93 \\
\hline & & 1695 & 8.97 \\
\hline Wyodak & & 1701 & 4.90 \\
\hline & & & 7.26 \\
\hline Demin. Wyodak & & 1702 & \\
\hline
\end{tabular}

NOTES:

$k_{n}=$ normalization factor

* amounts based on peak height

Work also continued on the development of a curve resolving program to analyze the OH region of the FT-IR spectrum. Problems with curve resolving routines are associated with the initial choice of parameters for input to the program. It is essential to have a prior knowledge of the number of bands in the region that is to be resolved as well as good initial estimates of the peak position of each band 
and its width and half height. One way to help with the choice of the initial inputs to the program is to examine the second derivative of the original coal spectra. However, the problem with this approach is that small peaks may be obscured by the noise level, thus underestimating the number of peaks.

A second approach is to examine the solid state spectra of every possible component separately to determine the number of peaks and peak positions as inputs to the program. This would not necessarily provide the right peak positions for an actual coal sample, but would provide a good idea of the number of distinct peaks.

Our approach to assessing the performance of a particular set of input parameters is to do curve resolving with coals and modified coals where there is good literature evidence of changing functional group concentrations due to the modification. This approach was followed by Starinsic et al. (1984) who determined the change of the carboxyl group content due to demineralization and ion exchange.

While it seems to be difficult to resolve all of the various constituents in the carboxyl $\left(1700 \mathrm{~cm}^{-1}\right)$ region, an examination of model compound hydroxides shows a simpler picture.

a. All hydroxides have a broad band around $3500 \mathrm{~cm}^{-1}$, except for the ortho-dihydroxides which have one or two additional peaks in the $3500-3600 \mathrm{~cm}^{-1}$. This feature will allow us to see them separately by including two bands in this region.

b. What interferes with this simple picture are the ortho-aliphatic monophenols and, to a lesser extent, condensed ring functionalities where the $\mathrm{OH}$ band is shifted towards higher wavenumbers. This kind of shift occurs also if the $\mathrm{OH}$ hydrogen becomes less hydrogen bonded.

c. There appears to be two or three bands in the $3600.3700 \mathrm{~cm}^{-1}$ region originating from the mineral content of the coal. These can either be subtracted using proper mineral spectra or added to the curve resolving scheme.

Based on these considerations, the synthetically constructed set of bands would consist of three mineral (3690, 3650, 3620), four $\mathrm{OH}$ (3550 for the dihydroxy, 3500, 3450 for the shifted and 3400 for the $\mathrm{OH}$ ) bands and three additional bands between 3200 and $3000 \mathrm{~cm}^{-1}$.

The observations from the preliminary work on curve resolving the $\mathrm{OH}$ region can be summarized as follows:

1. The peak around $3450 \mathrm{~cm}^{-1}$ is due to strongly absorbed $\mathrm{H}_{2} \mathrm{O}$ molecules which are removed upon drying the acid treated coal but not the $\mathrm{Ca}^{2+}$ treated or original (untreated) coal. 
2. The peak around $3400 \mathrm{~cm}^{-1}$ is the (mono)-phenolic peak. It increases after acid washing and cannot be back exchanged by $\mathrm{Ca}^{2+}$ below $\mathrm{pH} 8$.

3. The peaks around $3510 \mathrm{~cm}^{-1}$ and $3550 \mathrm{~cm}^{-1}$ are from ortho-dihydroxy groups and/or chemically bound water which are not removed by drying and show a maximum, along with the monophenols (or meta-para-diphenols), with hydrothermal pretreatment time.

Some preliminary results for curve resolving the $\mathrm{OH}$ region are shown in Table III-5. If this data is considered (on a qualitative basis) along with the data supplied in Table III-4 on carboxyl group changes, it can be seen that the changes in the free $\mathrm{COOH}$ and the o-dihydroxyl are usually in the same direction for each coal modification. One of the key findings of this work is that while carboxyl groups ion-exchange at $\mathrm{pH}=8.1$ and phenolic groups ion-exchange at $\mathrm{pH}>>8.2$, ortho dihydroxy functionalities ion-exchange at $\mathrm{pH}=7$ and thus behave like carboxyls. This unusual behavior is the result of intramolecular hydrogen bonding between the two neighboring oxygens to increase the resonance stability of the ortho-hydroxy-phenoxy radical or ion. Based on our work under a separate contract, which concerns water pretreatment of coal, we believe that the ortho-dihydroxy functions play a special role in promoting retrogressive reactions. Consequently, these functions will be further studied under the current program. 
TABLE III-5 - PRELIMINARY RESULTS OF CURVE RESOLVING THE OH REGION USING FT-IR METHODS FOR COALS AND MODIFIED COALS

\begin{tabular}{|c|c|c|c|}
\hline \multirow[t]{2}{*}{ Coal Type } & \multirow[t]{2}{*}{ Treatment } & \multicolumn{2}{|c|}{ DAF \% Arbitrary Units* } \\
\hline & & Phenolic - OH & Dihydroxy - OH \\
\hline \multirow[t]{4}{*}{ Zap } & $\cdots$ & 0.16 & 0.04 \\
\hline & $\mathrm{HCl}$ wash & 0.22 & 0.13 \\
\hline & $\begin{array}{l}\mathrm{Ca}^{2+} \text { load } \\
\mathrm{HCl} \text { wash }\end{array}$ & C.20 & 0.27 \\
\hline & Hydroth. pretr. $350^{\circ} \mathrm{C}, 20^{\prime}$ & $0.18-0.22$ & $0.07-0.20$ \\
\hline \multirow[t]{3}{*}{ Demin. Zap } & $\ldots$ & 0.17 & 0.14 \\
\hline & $\mathrm{Ca}^{2+} \mathrm{load}$ & 0.21 & 0.09 \\
\hline & $\begin{array}{l}\mathrm{Ca}^{2} \text { load } \\
\mathrm{HCl} \text { wash }\end{array}$ & 0.20 & 0.15 \\
\hline \multirow[t]{2}{*}{ Wyodak } & $\cdots$ & 0.15 & 0.03 \\
\hline & Hydroth. pretr. $350^{\circ} \mathrm{C}, 20^{\prime}$ & $0.25-0.27$ & $0.03-0.11$ \\
\hline Demin. Wyodak & $\cdots$ & 0.20 & 0.21 \\
\hline Zap & $\ldots$ & 0.16 & 0.04 \\
\hline Wyodak & $\cdots$ & 0.15 & 0.03 \\
\hline III. \#6 & $\ldots$ & 0.13 & 0.11 \\
\hline Pitt. & $\ldots$ & 0.08 & 0 \\
\hline
\end{tabular}

* Based on peak height 
"LZ" PETC/First Annual Report/523085

\section{TASK 3 - STUDIES WITH POLYMERIC MODEL SYSTEMS}

\section{A. Introduction and Objectives}

It has become increasingly clear in recent years not only that retrograde reactions substantially hinder the liquefaction of low-rank coals, but also that oxygen functional groups in the coal structure are major actors in these retrograde reactions. The evidence connecting oxygen groups to the formation of new, strong bonds, though convincing, is largely phenomenological in nature rather than mechanistic. Thus we know that crosslinking is correlated with the evolution of $\mathrm{CO}_{2}$ and $\mathrm{H}_{2} \mathrm{O}$ and therefore that carboxyl and/or phenolic groups are involved, but we do not know exactly how or why. In order to best mitigate the retrograde reactions it is necessary to better understand their mechanisms i.e., to know what factors promote and inhibit these reactions.

Task 3 complements the other tasks in this rroject in that it seeks to help understand why certain pretreatments tested with real coals are found to mitigate retrograde reactions and thus help lead to improved or different pretreatments. The approach to achieving this goal is to prepare and study the behavior of polymeric coal models under liquefaction conditions. This will provide us not only with starting materials and products that are both better known than is possible with real coals, but also with structures and reaction conditions that are more relevant to the liquefaction of real coals than are the typical "model compound" studies. Polymeric models should be more relevant to coals particularly with respect to mass-transport factors. The difficulty is not to make them too relevant: If the polymers are too much like real coals, both they and their products will be un-analyzable. Therefore, judicious choices are necessary as to what oxygen-containing structures are key to retrograde reactions in low-rank coals.

The first objective of Task 3 is to prepare po'ymer models having phenolic, carboxylic, and/or aryl ether groups considered to be important in low rank coals. There are two aspects to the choice of appropriate polymers: the choice of the polymeric backbone and the choice of the functional groups. One approach is to focus on the chemistry of the chosen functional groups in a polymeric matrix by selecting a polymer backbone that is itself not subject to cleavage under the reaction conditions. The other approach is to choose a backbone that is presumed to be coal-relevant and seek to understand its behavior first without, and then with, appended, relevant oxygen functional groups. We have planned to follow both of these approaches, using in the first case a refractory backbone of biaryl linkages (i.e., poly(phenylenes)), and in the second case a backbone having the major linkage type known to exist in lignins and presumed to be at least partially retained in low-rank coals. Thus far, the bulk of our effort - and progress - has been made in the second approach, including background studies on the behavior of carboxylic acids under coal liquefaction conditions. In this report, we describe each of these aspects in turn. 


\section{B. Work Performed}

\section{Synthesis of Polymers with a Polypherlylene Backbone}

The desire to emulate coal by studying the behavior of an insoluble polymeric model must of course be tempered by the fact that insoluble polymers are exiremely difficult to characterize. Accordingly, the philosophy we adopted was to generate a low-molecular weight oliogomer of poly (phenylene) that would be be soluble enough to permit characterization and functionalization and yet be high enough in molecular weight such that reactions at one unit of the polymer would generate species in close proximity to other units, rather than being totally isolated by intervening solvent, as is often the case in the reactions of monomeric model systems. At the time of writing the proposal, poly (phenylene) was commercially available as a potential starting point for functionalization, but by the beginning of the project, this was no longer the case, and a special synthesis became necessary. Following this approach, we settled on a synthesis targeted at octa(phenylene), or $\mathrm{C}_{6} \cdot \mathrm{H}_{6}-\left(\mathrm{C}_{6} \mathrm{H}_{4}\right)_{n}-\mathrm{C}_{6} \mathrm{H}_{6}$, where $n=6$.

We followed the procedure of Bamfield and Quam (1978) which involves heating a paste of bromoarenes, water, sodium formate and $\mathrm{Pd} / \mathrm{C}$. We used a 1:1 molar mixture of 4,4'-dibromobiphenyl and 4-bromobiphenyl to maximize the chances for octa(phenylene) $(n=6)$.

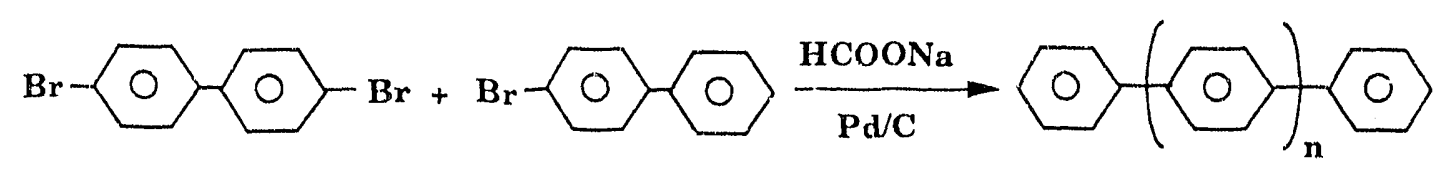

The reaction products turned out to be very insoluble and dificult to purify. Tetra(phenylene) is reported to be insoluble in ether (Handbook of Chemistry and Physics, 1976 a), and the higher oligomers can only be less soluble. Presumably it is molecular stiffness and the $\pi-\pi$ cloud interaction that makes these materials so insoluble at such low molecular weights. In fact, mass spectral analysis of the crude mixture using desorption chemical ionization showed not only a fair amount of hexa(phenylene) ( $n=$ $4, m / z=438$ ), but also additional peaks at $m / z 270$ and 284 (whose source we are not certain of). The insolubility of these products makes them difficult to work with, and if the unfunctionalized polymer is so insoluble, we doubt if we will be able to prepare well-characterized polymers in anything approaching the 10,000 Da range we had originally selected for emulation of the crosslinked coal molecule. We will consider other polymeric substrates that might serve as the backbone, but there are no structural types other than poly (phenylenes) that provide a polymer backbone that is truly refractory under liquefaction conditions. It is interesting to note that 1,3,5-triphenyl benzene, having the same molecular weight as the sparingly soluble linear tetraphenylene, is reported to be soluble in ether (Handbook of Chemistry and Physics, 1976 b), and it is possible that some approach could be devised based on this non-linear 
poly-aryl. However, concurrent work ha? shown one of the alternative approaches using more inherently coal-related (and more reactive) C.C.O linked polymers is simpler and more promising than we had thought.

\section{Synthesis of C.C.O Polymers}

The C.C.O " $\beta$-ether" linkage between adjacent aromatic rings is the most abundant linkage in lignins, from both angiosperm and gymnosperm sources. In the absence of evidence to the contrary, we have assumed that some significant fraction of these linkages survive into the low-rank coals. If these linkages are important in lignites and suwbiturnirous coals, they provide a very interesting situation. The $\beta$-ether linkage is known to be quite labile, via a tree radical chain reaction, under coal liquefaction conditions (Poutsma, 1987). In its simplest form, in phenylphenethyl ether $\left(\mathrm{C}_{6} \mathrm{H}_{5} \cdot \mathrm{O} \cdot \mathrm{CH}_{2} \cdot \mathrm{CH}_{2} \cdot \mathrm{C}_{6} \mathrm{H}_{6}\right)$, the $\beta$-ether linkage has a half life at $400{ }^{\circ} \mathrm{C}$ of 120 minutes, forming styrene and phenol (Gilbert and Gajewski, 1982). Thus one might speculate that if lignite were composed sutstantially of such linkages, it would simply fall to pieces under liouefaction conditions- unless retrograde reactions were very facile. Indeed, in the previous contract, we found that two different polymers presumably consisting largely of the $\beta$-ether linkage shoved both facile cleavage and extensive crosslinking. However, this, observation was clouded by the fact that side reactions could not readily be eliminated in the polymer synthesis (using mercuric trifluoracetate of 4-allylphenol and eugenol (2-methoxy-4-allylphenol)), and we were never able to obtain polymers that gave the correct elemental analysis. For this reason, more extensive study and interpretation of those polymer preparations was judged to be premature.

In the current work, we have successfully tested a new route to these C-C.O polymers, and we believe they re-emerge as the better route to address, in a polymeric context, the question of the effect of decarboxylation and other factors on crossliniking in low-rank coals.

The potential atternate direct synthesis of C.C.O bridged polymeis we have explored involves reaction of 4-hydroxyphenethyl bromide (or its analogs) in base, a reaction that in principle looks very simple. In practice, it is difficult to prevent the formation of unwanted products via a rapid intramolecular displacement that gives an intermediate spiroketone. However, we have been able to find phase transter catalysis conditions where the activity of $\mathrm{OH}$. is sufficient to initiate polymerization by opening the intermediate spiro compound, but the base concentration is insufficient to intertere with successful propagation to form moderate molecular weight C-C.O polymer.
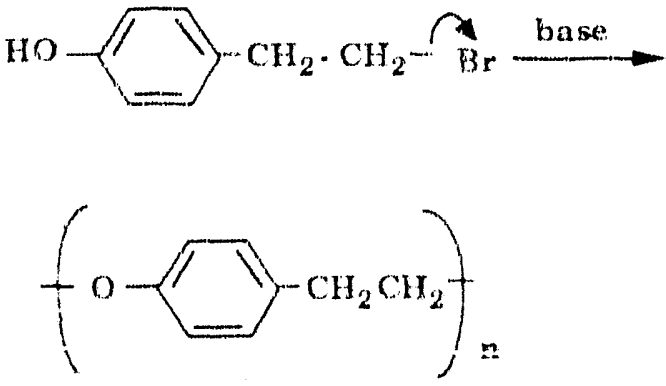

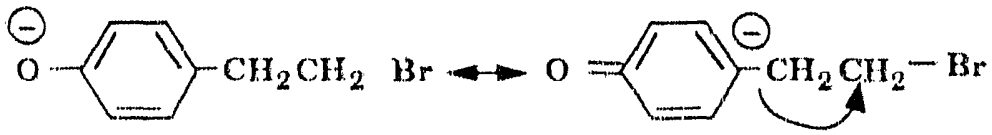

OH"Phase Transfer Catalysis

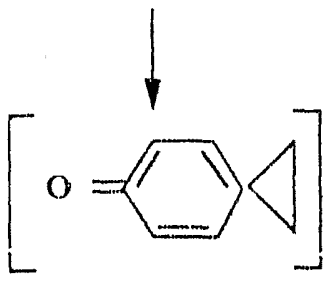


NMR analysis shows this product to have the carbon- $\mathrm{Br}$ bond in the starting material replaced by a carbon-oxygen bond, i.e., to consist of the desired C.C.O polymer. We determined the molecular weight distribution by gel-permeation chromatography (GPC) using THF as the solvent. Two different polymer fractions were analyzed: one was completely soluble, in THF and the other was only about $70 \%$ soluble. The molecular weight distribution of the latter, of course, applies only to the soluble portion. The weight average molecular weights were about 1150 and 2100 , respectively, corresponding to about 10 and 17 monomer units in the average molecules. About $25 \%$ of the second sample (THF-soluble portion) had a molecular weight above $3000 \mathrm{Da}$. We anticipate that minor modifications of the synthesis procedure will increase the molecular weight substantially; in any case, solubility fractionation of the mixture will allow us to separate, characterize, functionalize, and use a higher molecular weight portion, such as that soluble in warm dimethylformamide.

We plan, in the next quarter, to make larger quantities of the $-\mathrm{Ph}-\mathrm{O} \cdot \mathrm{CH}_{2} \mathrm{CH}_{2}$. polymer for pyrolysis and liquefaction iests. Also, since 3-methoxy-4-hydroxyphenethyl alcohol (homovanillyl alcohol) is commercially available, we will also proceed with the synthesis of the 3-methoxy analog of the above polymer. Except for the missing methyl side chain, this polymer (- $\left.(\mathrm{m}-\mathrm{OMe}) \mathrm{C}_{6} \mathrm{H}_{3}-\mathrm{O}-\mathrm{CH}_{2} \mathrm{CH}_{2^{-}}\right)$is identical to the poiymer we could not obtain in high purity via direct polymerization of eugenol during the previous contract. With these two polymers in hand, we should then be in a very good position both to see whether the unusual cleavage and crosslinking behavior of the -O-C-O-linkage in lignins is mirrored by the behavior of the same linkage in alcohol-free polymers. We should also be able to modify these polymers to examine the impact of decarboxylation in a context that is arguably more coal-relevant than any previously used in polymeric coal model studies.

\section{The Behavior of Carboxyl Functions in a Coal Liquefaction Environment}

The dilemma posed by the desire to have a characterizable polymeric backbone constructed of units that have low solubility at even rather low molecular weights has forced us to reconsider our approach. We essentially face the problem that the multiple objectives of insolubility (behavior like coal) and substrate and product characterizability tend to be mutually exclusive. Accordingly, it became clear that additional understanding of the thermal behavior of the carboxylic and phenolic functions in coal-related monorneric systems was necessary in order to make truly appropriate choices for polymer and carboxyl function type before additional exiensive synthesis effort is made. These studies will also be needed to establish the baseline for considering the effect of polymeric environment. Carboxyl functions have been implicateci in the crosslinking of coals during at relatively low temperatures (Suuberg et al., 1985; Serio et a!, 1987), and Solomon and coworkers (Solomon et al., 1990) have been able to model the pyrolytic loss of solvent swelling by including one additional crosslink in the network for every $\mathrm{CO}_{2}$ evolved. Moreover, pretreatments that have been found to be effective in promoting liquefaction, have also shown a corresponding decrease in the early $\mathrm{CO}_{2}$ evolution (Serio et al., 1990). These results strongly suggest that carboxyi functions are involved in the low-temperature crosslinking of coals. 
However, the chemical reactions lirking decarboxylation with coupling have not been delineated. In a recent study, Siskin and coworkers (1991) showed that decarboxylation of naphthoic acid under hydrothermal conditions was attended by some binaphthyl; however, the coupling aspect was not elaborated in that study. We have examined the literature and conducted over 40 experiments with monomeric model compounds (including polycycylic) in organic media to see if crosslinking results directly from decarboxylation, and how crosslinking may be affected by ion exchange, the presence of a hydrothermal environment, and other conditions relevant to pretreatments we are testing in this project.

Decarboxylation Literature. Examination of the literature on decarboxylation (March, 1985; Cohen and Schambach, 1970, Friedel, 1958, Hites and Biemann, 1972), as well as earlier results obtained at SRI on decarboxylation under coal liquefaction conditions (McMillen, 1985), allow us to make the generalization that coupling is not typically a widespread result of decarboxylation (except for the "dry" pyrolysis of alkaline earth salts (Friedel, 1§58, Hites and Biemann, 1972). Beyond this generalization, we will make only limited reference to this earlier work: little of it had the specific goal of assessing the associated coupling, and much of it was low-temperature studies of structures specifically activated towards decarboxylation. Nevertheless, from the observation that decarboxylation of many acids occurs without substantial coupling (March, 1985, Cohen and Schambach, 1970, Friedel, 1958; Hites and Biemann, 1972, McMillen, 1985, McMillen et al., 1981), we draw the preliminary conclusions first, that it is critical to choose appropriate structures and conditions for decarboxylation of coal relevant polymeric models, and second, that there is reasonable hope for finding coal liquefaction for pretreatment) conditions that significantly decrease any coupling that results from decarboxylation. In the following subsections we first summarize the results of the decarboxylation experiments performed in this project, and then in summary present a somewhat broader discussion of decarboyxlation as it applies to coal liquefaction, drawn from these recent experiments as well as from earlier SRI work and data in the literature.

The Decarboxylation of Activated and Unactivated Benzoic Acids. The carboxylic acids shown in Table IV-1 have been subjected to "liquefaction" conditions and the products analyzed by gas chromatography to determine the extent of decarboxylation and coupling that resulted.

The data in this table demonstrate that the decarboxylation of benzoic acid itself is slow at $400{ }^{\circ} \mathrm{C}$ in tetralin (3-5\% in $1 \mathrm{hr}$ ), unless a fairly strong base or other decarboxylation promoter is present. Surprisingiy: the decarboxylation of calcium benzoate in tetralin is no faster than that of the free acid. With respect to coupling, we see that when decarboxylation is promoted by bases, there is little or no evidence for coupling, either with benzene, tetralin, naphthalene, or even the very good acceptor, pyrene. This absence of coupling, together with the slow decarboxylation of benzoic acid itself at $400^{\circ} \mathrm{C}$, raises the question whether unactivated aromatic carboxylic acids actually represent the acid species that undergo facile decarboxylation between 250 and $350^{\circ} \mathrm{C}$ during the heating of low-rank coals. 


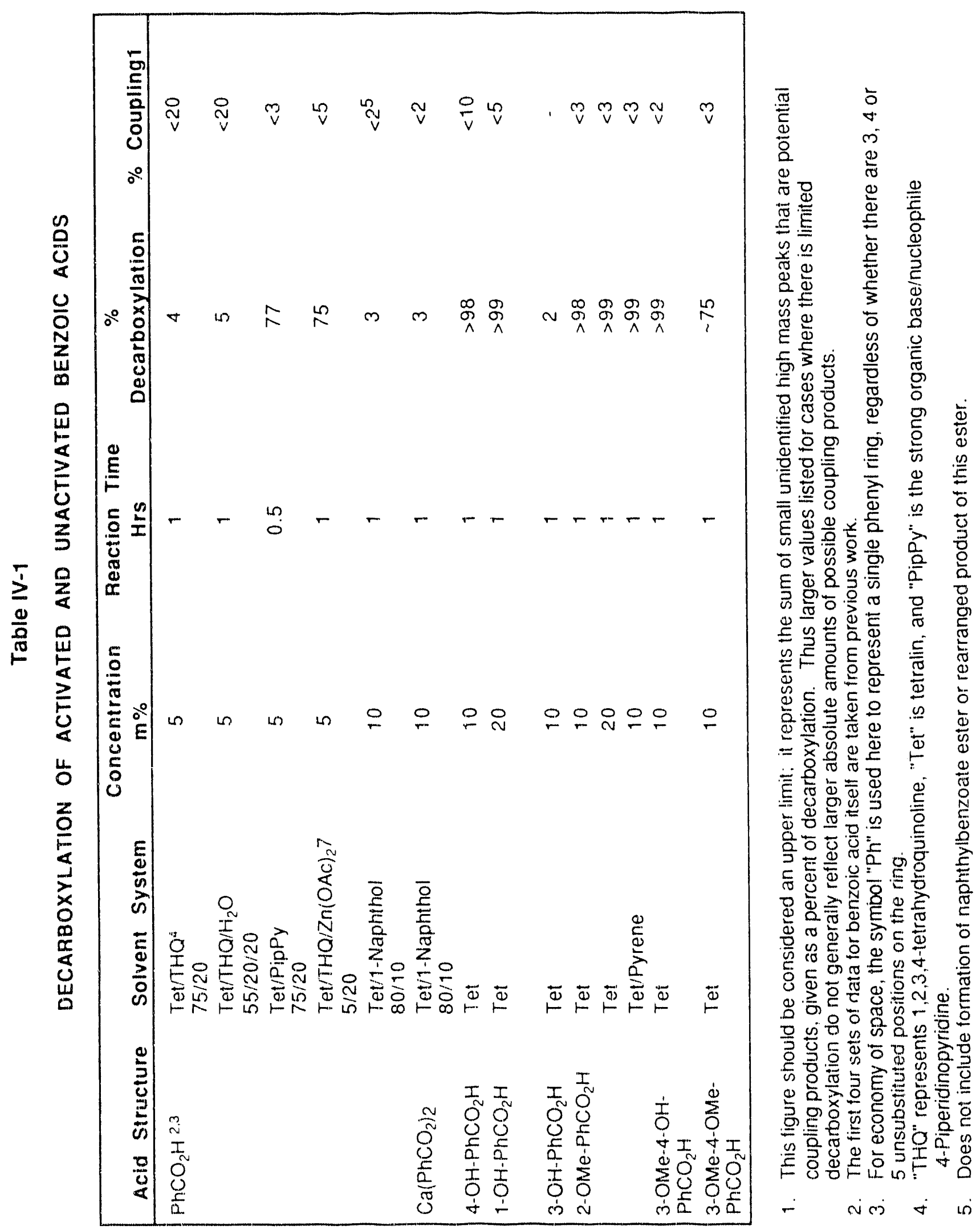


Therefore, we performed additional experiments to examine the behavior of benzoic acid derivatives known (March, 1985, Cohen and Schambach, 1970) to be activated toward decarboxylation via electrophilic attack. Thus far, we have tested the ortho- and para- substituted acids listed in Table IV-1. For all of these, except for the meta hydroxy acid and veratric acid (3-OMe-4-OMe- $\mathrm{C}_{6} \mathrm{H}_{3} \mathrm{CO}_{2} \mathrm{H}$, last row in Table IV-1), decarboxylation in tetralin was complete in one hour at $400^{\circ} \mathrm{C}$. Again however, there was no substantial level of coupling products. (In some cases there were small chromatographic peaks, as yet unidentified, at higher retention times. We cannot rule out the possibility that these result from some type of coupling associated with decarboxylation, but in any case they amount to less than $5 \%$ at most of the decarboxylated acid.) For the meta-hydroxy acid, there was, as expected, very little decarboxylation.

Perhaps the most interesting result with the activated acids is that obtained with veratric acid, the only one of the activated acids not possessing a free phenolic $\mathrm{OH}$. This acid did not undergo complete decarboxylation, but was recovered in ca. $25 \%$ yield after 1 hour in tetralin at $400{ }^{\circ} \mathrm{C}$, in contrast to the analog containing a free $\mathrm{-OH}$ in the same position, which underwent complete decarboxylation. Because $\mathrm{p}$-OMe is generally just as activating toward electrophilic attack as $\mathrm{p}-\mathrm{OH}$, the above difference indicates that the rate determining step cannot simply involve attack on the starting material itself. That is, this result suggests that the principal mode of decarboxylation by electrophilic attack either involves reaction of the phenoxy anion or the keto form of the phenolic acid, which is accessible only through the free phenol. Alternatively, the keto form might simply undergo thermal unimolecular bond cleavage (homolysis) to yield a stabilized radical (phenoxy) and the radical $\mathrm{CO}_{2} \mathrm{H}$, even through the latter is not a particularly stable radical.

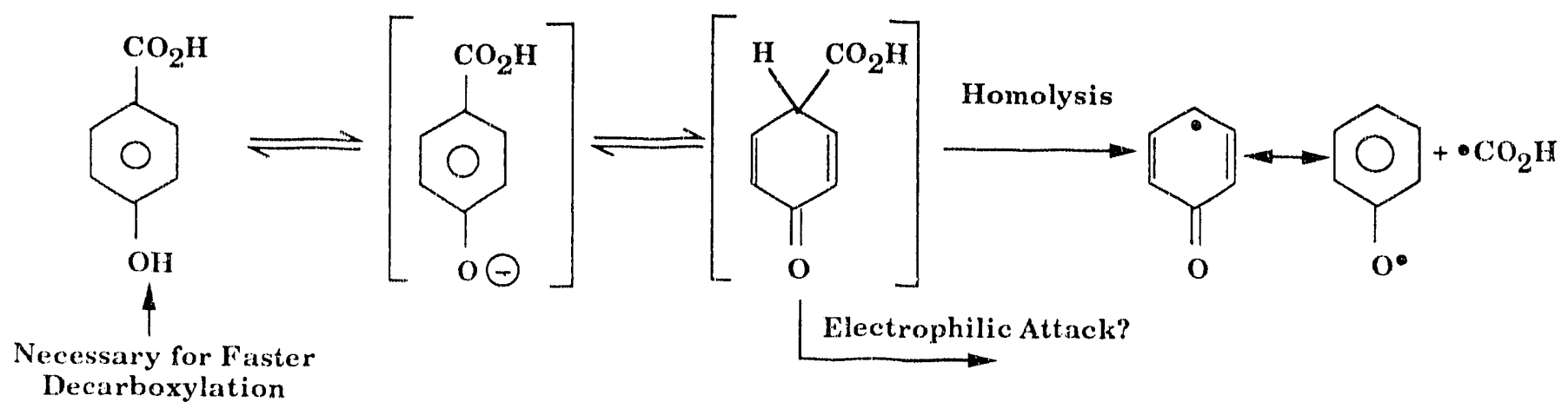

Assuming that a pre-equilibrium between the phenol and the keto-form is rapidly established and the homolysis of the keto-form would be the rate determining step, the net rate of decarboxylation can be readily estimated, since this case is exactly analogous to that described in the literature for benzyl phenols and phenoxy phenols (McMillen et al., 1981). This procedure leads to an estimated half-life at $400{ }^{\circ} \mathrm{C}$ of 1000 to 10,000 hours. Since the thermochemical estimates should be reasonably accurate here, and the assumption of a rapid pre-equilibrium leads to a lower limit on the half-life, we conclude that decarboxylation through homolysis of the keto-form can be ruled out as the reason for faster reaction of the acid containing a free $\mathrm{OH}$ in the para position. 
The remaining alternatives for reaction via the anion or keto-form do not appear particularly compelling, but we expect this issue will be clarified in the course of answering the ultimate question, "What are the conditions that enable decarboxylation to result in coupling?" In the meantime, the observation of very little coupling during the decarboxylations shown in Table IV-1 allows us to identify the following changes in substrate structure/reaction conditions that perhaps make the decarboxylation experiments more relevant to the conditions that actually prevail during liquefaction and also more likely to facilitate coupling, while yet remaining simple enough to provide chemical understanding.

Conditions likely to promote coupling in conjunction with decarboxylation:

1. Increased concentration and/or improved coupling partners for aryl radicals;

2. Decreased concentration of radical scavengers.

3. Electron-transfer agents that may convert carboxylate anions to radicals, which then decarboxylate to yield aryl radicals;

4. Conversion of the acids to their $\mathrm{Ca}$ or $\mathrm{Mg}$ salts, forms known in the coals themselves to increase char formation, and in alkane carboxylic acids (Hites and Biemann, 1972) to yield ketone coupling products;

5. Addition of structures that may couple by forming electrophilic agents that attack the acids themselves, rather than merely react with aryl radicals produced in decompostion of the acids.

Item 1 has already been partially addressed with several of the experiments listed in Table IV-1, and did not result in significantly increased coupling. Items 2 and 3 are dealt with in considerable detail in the experiments described in the following subsection. Regarding Item 4, preliminary experiments with calcium benzoate (in solution, rather than neat) have not yielded addtional coupling products, and Item 5 has not yet been experimentally addressed.

The Effect of Electron-Transfer Agents and the Acceptor/Scavenger Ratio. Because of the low levels of coupling products observed in the experiments described above, where we were attempting to grossly simulate the donor solvent environment of liquefaction by using tetralin or tetralin mixtures as the reaction medium, most of the remaining experiments were performed in more oxidizing systems, i.e., without either hydro or alkylaromatic species in the mixture. In these experiments we used mixtures of benzoic acid/naphthalene as the basic system and then added various combinations of the reagents that were found from our previous studies to affect decarboxylation, particularly base (pyridine) and the potential electron transfer agents $\mathrm{Fe}_{3} \mathrm{O}_{4}$ and $\mathrm{Cu}(\mathrm{OAC})_{2}$. In addition, we have performed a few experiments with phenylacetic acid to examine the behavior of a prototypical aliphatic acid. 
In this portion of our decarboxylation studies, we have restricted the range of acids and broadened the range of reaction conditions under which these acids are being heated, in an attempt to bring about some coupling under conditions that perhaps approximate more closely those encountered in the thermal processing of low rank coals. In brief, we have tried various changes in reaction conditions that should make it more likely to form (from an un-activated acid) the carboxylate anion and oxidize it to the carboxyl radical, which should then readily decarboxylate to the phenyl radical. Under these conditions, literature data for the reactions of phenyl- and other aryl radicals (Fahr and Stein, 1988, Chen et al., 1984) lead us to expect that any phenyl radicals formed will add very readily to essentially any aromatic system, displacing hydrogen to form biaryl linkages. We have allowed benzoic acid to react (at $400^{\circ} \mathrm{C}$ ) in the presence of varying amounts of naphthol, napthalene, and methylnaphthalene, as well as tetralin, and have used the calcium salt of benzoic acid and pyridine as bases and $\mathrm{Fe}_{3} \mathrm{O}_{4}$ and $\mathrm{Cu}(\mathrm{OAc})_{2}$ as electron-transfer agents. We performed a total of 21 experiments with cupric acetate or iron oxide, most of which we do not show in this report. The major differences between these two one-electron oxidants can be seen in the results shown in Table IV-2.

Both agents markedly increase decarboxylation (from 3-5\% as shown in Table IV-1 to at least $\sim 60 \%$ as seen in Tabie IV-2). Decarboxylation rates are at least ten times faster with $\mathrm{Cu}(\mathrm{OAC})_{2}$ than with $\mathrm{Fe}_{3} \mathrm{O}_{4}$, but the coupling is about ten times faster in the presence of $\mathrm{Fe}_{3} \mathrm{O}_{4}$. For present purposes, the results can be summarized as follows. The combination of pyridine and cupric acetate did enhance decarboxy!ation substantially, as the literature (March, 1985, Cohen and Schambach, 1976) indicates it should. However, we still see only very low levels of coupling products (other than ester formation from benzoic acid and naphthol, when it is present). Furthermore, we see this lack of substantial coupling even when we have replaced most or all of the tetralin with naphthalene to provide more good acceptors for phenyl radicals and to decrease the scavenging ability of the system. Under these latter conditions, reported phenyl radical $\mathrm{H}$-abstraction (from tetralin) and aryl radical addition rates (Fahr and Stein, 1988, Fahr et al., 1986, Chen et al., 1989) suggested that the addition should nci ve overwhelmed by scavenging of the phenyl radicals. Thus, from the data in Tables IV-1 and IV-2, it is still far from evident what chemical factors are here not allowing substantial coupling, but which may still allow such coupling during coal conversion.

After a few experiments with $\mathrm{Cu}(\mathrm{OAC})_{2}$ and the mixed iron oxide $\mathrm{Fe}_{3} \mathrm{O}_{4}$, we switched to $\mathrm{Fe}_{3} \mathrm{O}_{4}$ because (1) coupling was greater with iron oxide and the parameters affecting it could be more readily explored, (2) iron is more coal.relevant than copper and (3) decomposition of the acetate led to unwanted buildup of non-condensible gases (presumably methane) and perhaps distorted chemistry because of the demand of methyl radicals for hydrogen. Iron sulfides and iron sulfates are of course also relevant, but we have, for the time being, confined our iron-promoted decarboxylation studies to $\mathrm{Fe}_{3} \mathrm{O}_{4}$ in order to focus ine impact of changing the organic structural parameters. 
Table IV-2

EFFECTS OF DIFFERENT 1-ELECTRON OXIDANTS ON COUPLING AND DECARBOXYLATION OF BENZOIC ACID DURING REACTION AT $400^{\circ} \mathrm{C}$ FOR 1 HIOUR

\begin{tabular}{|c|c|c|c|c|c|c|c|c|c|c|}
\hline \multirow[b]{2}{*}{ Exp. } & \multicolumn{5}{|c|}{ Reactants $(\mathrm{mol} \%)^{a}$} & \multicolumn{5}{|c|}{ Results } \\
\hline & $B A$ & Naphth. & Pyridine & $\mathrm{Fe}_{3} \mathrm{O}_{4}$ & Cu Acet. & $\%$ Unr. Acid & $\%$ Ph-Naphb & $\%$ Py-Na'shb & $\%$ Binaph. ${ }^{b}$ & $\%$ Decarbox.c \\
\hline 1 & 11.3 & 68.8 & 9.8 & 10.1 & - & 19.5 & 3.2 & 2.93 & 2.66 & 57.3 \\
\hline 2 & 10.4 & 70.4 & 8.9 & - & 10.3 & $<0.1$ & 0.28 & 0.65 & 2.03 & 83.4 \\
\hline
\end{tabular}

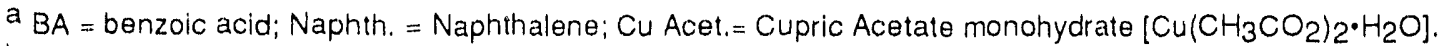

b Ph-Naph = 1 and 2-phenyl naphthalene; Py-Naph = pyridinylnaphthalenes; Binaph. = binaphthalenes. Results are given as a mol\% of the starting benzoic acid. It has thus been assumed that pyridinylnaphthalenes and binaphthalenes are coupling products that stem from decarboxylation after a shift of the radical center from the initial phenyl radical to either pyidine or naphthalene. This assumption is being checked and could be incorrect.

$c$ Based on identified decarboxylated products including benzene and phenyl-containing coupling products. 
Coupling Product Distribution. The nature and distribution of the coupling products themselves may provide an indication of the factors limiting coupling under the above reaction conditions. For the decarbozylation of benzoic acid in naphthalene, pyridine and $\mathrm{Fe}_{3} \mathrm{O}_{4}, \mathrm{GC} / \mathrm{MS}$ analysis has allowed us to identify the coupling products 1- and 2-phenylnaphthalene, two isomers of pyridinylnaphthalene, and the 1,1', 1,2', and 2,2'-binaphthyls, as listed in Table IV-3.

Typically the 1-phenyl naphthalene is two to three times more abundant than the 2-phenylnaphthalene, in accord with the relative rates of radical addition and $\mathrm{H}$-transfer to naphthalene that have been reported in the literature (Herndon, 1981; McMillen et al., 1987). In the case of the binaphthyls, the ratio of 1,2'-, $1,1^{\prime}-$, and $2,2^{\prime}$-binaphthyl is typically $3: 2: 1$. This product distribution is not in accord with the slightly higher thermodynamic stability of the 1-naphthyl radical, but is in accord with the known preference (Fahr et al., 1986; Chen et al., 1989) for addition to the 1-position of the naphthalene ring. In any case it is the same product distribution as reported by Stein et al. (1987) for radical induced binaphthyl formation. In the case of the pyridinyl naphthalenes, the point of connection of the pyridine to the naphthalene ring is inferred from the phenyl naphthalenes, but the connections to the pyridine ring are unknown. At this point we judge that the isomer distributuions are generally consistent with $\mathrm{H}$-abstraction from either pyridine or naphthalene by the initially produced phenyl radical, followed by addition of the new aryl radical to naphthalene. However, the formation of similar amounts of pyridinyl naphthalenes and naphthylnaphthalenes is surprising in view of the fact that the reaction mixture contains seven times as much naphthalene as pyridine.

The decarboxylation products observed in more oxidizing systems (no donor solvent present, but with an added electron-transfer agent) tend to support the basic mechanism anticipated from the literature (March, 1985) and outlined below, whereby the benzoic acid is converted to benzoate by the base (1) and the benzoate anion to the radical by the electron transfer agent (2). The carboxyl radical then decomposes to $\mathrm{CO}_{2}$ and phenyl radical (3). Phenylnaphthalenes result from net displacement of a naphthyl hydrogen by phenyl radical (4). If the phenyl radical were to abstract hydrogen from pyridine or naphthalene prior to successful addition, pyridinyl and naphthyl radicals would result. Attack of these secondary radicals on naphthalene could then explain the formation of pyridinylnaphthalenes and binaphthalenes, as briefly indicated above.

$$
\begin{aligned}
\mathrm{C}_{6} \mathrm{H}_{6} \mathrm{CO}_{2} \mathrm{H}+\mathrm{C}_{6} \mathrm{H}_{6} \mathrm{~N} & \rightarrow \mathrm{C}_{6} \mathrm{H}_{5} \mathrm{CO}_{2}+\mathrm{C}_{6} \mathrm{H}_{6} \mathrm{NH}^{\cdot} \\
\mathrm{C}_{6} \mathrm{H}_{6} \mathrm{CO}_{2}+\mathrm{Fe}_{3} \mathrm{O}_{4} & \rightarrow \mathrm{C}_{6} \mathrm{H}_{6} \mathrm{CO}_{2} \bullet \mathrm{Fe}_{3} \mathrm{O}_{4} \\
\mathrm{C}_{6} \mathrm{H}_{6} \mathrm{CO}_{2} \bullet & \rightarrow \mathrm{C}_{6} \mathrm{H}_{6} \bullet+\mathrm{CO}_{2} \\
\mathrm{C}_{6} \mathrm{H}_{6} \bullet+\mathrm{C}_{8} \mathrm{H}_{10} & \rightarrow \mathrm{C}_{6} \mathrm{H}_{6} \cdot \mathrm{C}_{8} \mathrm{H}_{10}+\mathrm{H} \bullet
\end{aligned}
$$

It is interesting that a mechanism for the widely used copper/quinoline-promoted decarboxylation of aromatic acids was suggested as recently as 1970, and is still no: entirely clear. There is very likely more than one mechanism for transition metal catalyzed decarboxylations operative for different substrates under different conditions. 


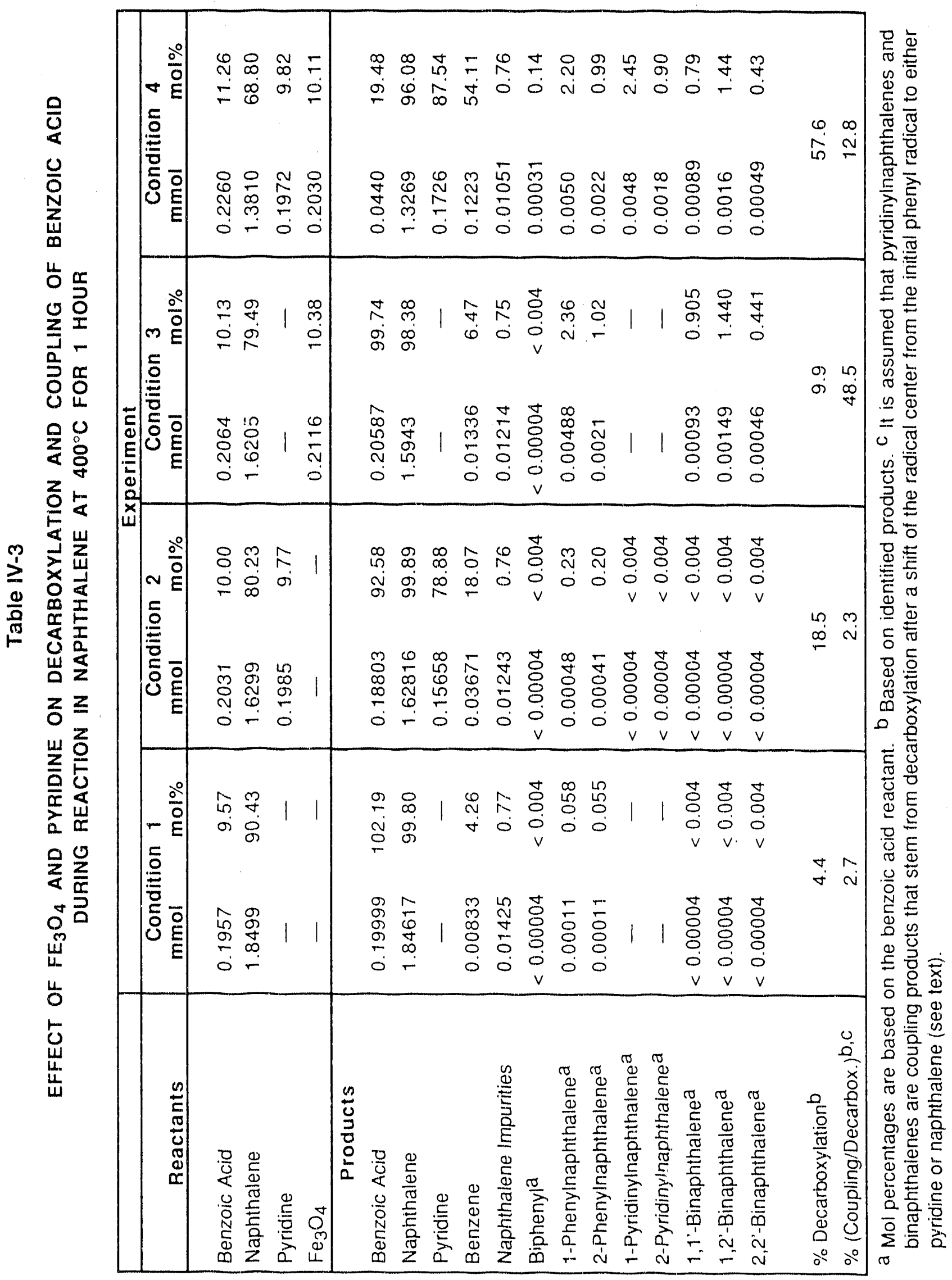


The Effect of Iron Oxide and Base on Coupling. The four experiments in Table IV-3 also show the separate and combined impacts of iron oxide and pyridine on decarboxylation and coupling. All of the products discussed above are listed in this table, but the major points are contained in the first four rows, where the reactant identities and concentrations are listed, and the last two rows, where the percent decarboxylation and the percent of decarboxylation that leads to coupling are shown. It can be seen that the conditions strongly effect both the amount of decarboxylation and the degree of coupling. In naphthalene only (Condition 1), benzoic acid undergoes about $4.4 \%$ decarboxylation and only $2.7 \%$ of the decarboxylated material is found as the coupling product phenylnaphthalene. The addition of pyridine base (Condition 2) increases decarboxylation by a factor of four, but the fraction of decarboxylation that leads to coupling products is unaffected, remaining at $2.5 \pm 0.2 \%$. These results are consistent with a mechanism where decarboxylation involves primarily the carboxylate anion itself. To the extent that phenyl anion is the initial product of decarboxylation, its strong basicity is seems likely to have it abstract a proton rather than couple with another molecule. (FOOTNOTE Note that in the "dry" or neat pyrolysis of alkaline earth salts of alkane carboxylic acids (Hites and Blemann, 1972), where the products are ketones that apparently result from the attack of an alkyl carbanion on an adjacent metal carboxylate, all of the hydrogens except those alpha to the carboxyl group are many orders of magnitude weaker acids than a compound such as tetralin, which has benzylic hydrogens. Furthermore, in the pyrolysis of the neat salt, the chances that the carbanion will encounter another carboxylate group are clearly much enhanced. Just how relevant the pyrolysis of neat calicum alkanoates to coal conversion is not clear. It could be, for instance, that preferential alignment of carboxylic acid groups at mineral matter interfaces during the coalification process results in an effective concentration of carboxylates that is much higher than their average concentration in the coal structure.END FOOTNOTE) The effect of base is then to increase the concentration of the benzoate anion and hence the rate of decarboxylation. The product is still phenyl anion, however, and the rate of coupling is therefore unaffected.

Substantial coupling is seen only in those systems where the 1 -electron oxidant $\mathrm{Fe}_{3} \mathrm{O}_{4}$ has been added (Conditions 3 and 4). By itself, the addition of $\mathrm{Fe}_{3} \mathrm{O}_{4}$ leads to a factor of 2.5 increase in the rate of decarboxylation when compared with the naphthalene-only system. More significant, however, is the fact that now nearly one-half of the decarboxylated material is found as a coupling product. This result is consistent with the traditional organic chemistry picture of decarboxylation of aryl carboxylic acids outlined above, namely that the benzoate anion is oxidized to the carboxylate radical, which then loses $\mathrm{CO}_{2}$ to give a phenyl radical. Phenyl then displaces a hydrogen from naphthalene to give phenylnaphthalene. Alternatively, phenyl can abstract a hydrogen from naphthalene to give naphthyl radical, which can then displace a hydrogen from naphthalene to give binaphthyl. At present, we are assuming that this is the source of essentially all the binaphthyl. This is being checked by the reaction of naphthalene $/ \mathrm{Fe}_{3} \mathrm{O}_{4}$ alone. 
When both pyridine and $\mathrm{Fe}_{3} \mathrm{O}_{4}$ are added (Condition 4), the degree of decarboxylation increases to about $60 \%$. However, the fraction of decarboxylated material that couples is only $12.8 \%$, a factor of 3.8 lower than with $\mathrm{Fe}_{3} \mathrm{O}_{4}$ only, but a factor of 5 greater than with no added $\mathrm{Fe}_{3} \mathrm{O}_{4}$. Apparently the base directly or indirectly facilitates the transfer of a hydrogen to phenyl radical before it can couple. Notice that this effect of added base in suppressing the fraction of decarboxylation that leads to coupling was not observed in the absence of $\mathrm{Fe}_{3} \mathrm{O}_{4}$ (compare the results for Conditions 1 and 2), consistent with the supposition that in the absence of $\mathrm{Fe}_{3} \mathrm{O}_{4}$ the bulk of the decarboxylation goes through a different species. Although these observations on the effect of the base are at present not fully understood, they obviously could have ramifications with regard to the design of a system which minimizes coupling reactions in coal liquefaction.

The Effect of Water. Because water has figured prominently in various coal pretreatment studies and because it has been shown to inhibit the coupling of phenolic structures, we added 10 mol\% water to the system which has so far shown the greatest coupling (as a fraction of decarboxylation), namely the benzoic acid-naphthalene- $\mathrm{Fe}_{3} \mathrm{O}_{4}$ system. In the this case, however, there was no significant impact of water, either on decarboxylation or on coupling.

The effect of H-Donors. Although as described above, we removed $\mathrm{H}$-donors from the reaction mixtures in an attempt to produce enough coupling products so that the factors affecting their formation could be readily studied, we did not show above any single direct comparison of the impact of donors. Table IV-4 shows that the replacement of roughly half of the naphthalene with the H-donor tetralin decreased not only the fraction of the decarboxylation that eventually led to coupling, but also the extent of decarboxylation.

As discussed above, it was expected that the $\mathrm{H}$-donor, functioning in its radical scavenger mode, would scavenge a larger fraction of the phenyl radicals before they could couple. However, we did not anticipate that the $\mathrm{H}$-donor would also decrease the amount of decarboxylation, and we are not now able to rationalize this result. It would seem unlikely that that an initially produced carboxyl radical would have a sufficiently long lifetime before decarboxylation to allow any significant scavenging by tetralin.

Decarboxylation of Phenyl-Subsituted Alkane Carboxylic Acids. Since we do not know the distribution of carboxylic acid types in these coals, and since the oxidation of non-benzylic alcohol carbons in the original lignin structure is an alternative to oxidation of benzylic carbons to substituted benzoic acids, we have performed a few experiments on phenylacetic acid. This structure, having the carboxyl carbon $\beta$ - to the aromatic ring, should be a reasonable prototype for all acids having the carboxyl carbon $\beta$ - or further from the aromatic ring. Table IV-5 shows that the decarboxylation of this aliphatic acid, which in tetralin alone is about six times higher for phenylacetic acid than it is for benzoic acid in tetralin alone, is also markedly accelerated by electron-transfer agent and base. 


\section{Table IV-4}

EFFECTS OF SOLVENT H-DONATING ABILITY ON COUPLING AND DECARBOXYLATION OF BENZOIC ACID DURING REACTION AT $400^{\circ} \mathrm{C}$ FOR 1HOUR IN PRESENCE OF BASE AND THE ELECTRON TRANSFER AGENT CUPRIC ACETATE

\begin{tabular}{|c|c|c|c|c|c|c|c|c|c|c|}
\hline \multirow[b]{2}{*}{ Exp. } & \multicolumn{6}{|c|}{ Reactants $(\mathrm{mol} \%)^{\mathrm{a}}$} & \multicolumn{4}{|c|}{ Results } \\
\hline & $B A$ & Naphth. & Tet / MN & Pyridine & Naphthol & Cu Acet. & Qun Acid & $\%$ Coupling ${ }^{b}$ & $\%$ Decarbox. ${ }^{c}$ & $\%$ (Coup/Decarb) \\
\hline 1 & 9.8 & - & 58.8 & 12.2 & 9.6 & 9.7 & 45.9 & $0.51^{d}$ & 46.5 & 1.1 \\
\hline 2 & 10.4 & 70.4 & - & 8.9 & - & 10.3 & $<0.1$ & 2.96 & 83.4 & 3.5 \\
\hline
\end{tabular}

a $B A=$ benzoic acid; Naphth. = Naphthalene; Tet/MN $=50: 50$ molimol mixture of tetralin and 1-methylnaphthalene; Naphthol $=1$-naphthol; $\mathrm{Cu} A c e t .=$ Cupric Acetate monohydrate $\left[\mathrm{Cu}\left(\mathrm{CH}_{3} \mathrm{CO}_{2}\right)_{2} \cdot \mathrm{H}_{2} \mathrm{O}\right]$.

b Results are given as a mol\% of the starting benzoic acid and refer to all peaks in the coupling region of the chromatogram.

C Based on identified decarboxylated products including benzene and phenyl-containing coupling products.

$d$ This figure does not include $1 \%$ iormation of naphthyl benzoate from benzoic acid and naphthol. 
Table IV-5

EFFECT OF CUPRIC ACETATE AND PYRIDINE ON DECARBOXYLATION AND COUPLING OF PHENYLACETIC ACID DURING REACTION AT $400^{\circ} \mathrm{C}$ FOR 1 HOUR

\begin{tabular}{|c|c|c|c|c|c|c|c|c|c|}
\hline \multirow[b]{2}{*}{ Exp. } & \multicolumn{5}{|c|}{ Reactants (mol\%) } & \multicolumn{4}{|c|}{ Results } \\
\hline & Ph-AA & Tetralin & Naphth. & Pyridine & Cu Acet. & $\%$ Unr. Acid & $\%$ Coupling $^{b}$ & $\%$ Decarbox. ${ }^{c}$ & $\%$ (Coup/Decarb) \\
\hline 1 & 10.3 & 87.7 & - & - & - & 64.4 & 2.8 & 21.7 & 12.7 \\
\hline 2 & 9.5 & - & 71.3 & 9.3 & 9.9 & $<0.01$ & 15.7 & 85.9 & 18.3 \\
\hline
\end{tabular}

a $\mathrm{Ph}-\mathrm{AA}=$ phenylacetic acid; Naphth. = Naphthalene; Cu Acet. = Cupric Acetate monohydrate $\left[\mathrm{Cu}\left(\mathrm{CH}_{3} \mathrm{CO}_{2}\right)_{2} \cdot \mathrm{H}_{2} \mathrm{O}\right]$.

b Not all peaks have yet been identified; results are based on sum of all peaks in the region of expected coupling products.

c Based on sum of identified decarboxylated products such as toluene and all coupling products which are assumed to have been decarboxylated. 
However, it is curious that the extent of acceleration is actually less for this aliphatic acid than it is for benzoic acid. Although phenylacetic acid is inherently more reactive, the promoted decarboxylation is orly about $85 \%$ in one hour, as compared to $98 \%$ or greater with benzoic acid in the presence of $\mathrm{Cu}(\mathrm{OAC})_{2}$.

The extent of coupling that accompanies decarboxylation would seem (although some of the coupling products for phenylacetic acid have not yet heen identified to the extent that they have for benzoic acid) to be somewhat higher than for benzoic acid under comparable conditions. This is somewhat surprising, since no species seem more thermodynamically equipped to couple than aryl radicals: no other radicals form nearly as strong a bond when they add to another aromatic ring. However, an a-priori prediction would have been difficult here, since the aryl radicals also form a comparable stronger bond to $-\mathrm{H}$ in the act of being scavenged.

\section{Summary and Conclusions}

\section{Model Polymer Synthesis}

The preparation of polymer mixtures dominated by hexa(phenylene) showed that characterization and functionalization of moderate molecular weight polyphenylenes proves to be very difficult, owing to the insolubility even of these low molecular weight oligomers. On the other hand, the preparation of moderate molecular weight C.C.O polymers ( $n=10$ to 30 ) has proven to be easier than we had anticipated, after difficulties with unwanted side reactions were suitably mirimized with a phase-transfer catalyst approach. Although these polymers have a labile backbone and do not therefore provide a refractory framework with whish to study unencumbered the reactions of carboxylic acid groups we plan to attach to the polymers, these materials will constitute the mosi coal-related polymer models that have been studied to date. They will, therefore, provide very appropriate surrogates for addressing the retrograde reactions of phenolic and carboxylic acid functions.

\section{Decarboxylation and Coupling in Monomeric Systems}

From the results described above, logether with previous decarboxylation studies we have examined, we reach the following preliminary conclusions. First, simple benzoic acids (i.e., unsubstituted by anything except carbon; do not rapiciy decarboxylate below $400{ }^{\circ} \mathrm{C}$, except in the presence of strong base and or electron transter agents, and second, upon decarboxylation, they tend to form rather smaller amounts of coupling products than might have been expected, either with themselves or with aromatics that are part of the solvent systern. This is true even when the system contains no $H$.donor component that might be expested to scavenge aryl radical intermediates before they could couple. It is also true even when aromatics such as pyrene or naphthol, which are very good radical acceptors, have been added to the systerm. These low levels of coupling raise two important questions. First, is 
coupling associated with decarboxylation as important a part of retrograde reactions in low-rank coals as it has been assumed to be? Second, if decarboxylation is an important prelude to retrograde reactions with real coals, doesn't the rather low levels of coupling observed with model carboxylic acids suggest that this doesn't have to be so?

The electron-transfer agent cupric acetate, as expected from the literature, was very effective in promoting decarboxylation, but the fraction of this added decarboxylation that resulted in coupling was low, typically less than $10 \%$. The mixed iron oxide, $\mathrm{Fe}_{3} \mathrm{O}_{4}$, was somewhat less effective at promoting decarboxylation, but the fraction of the decarboxylation that results in coupling is 4 to 5 times higher. One very surprising observation was that pyridine, while promoting decarboxylation (as expected), decreased by a factor of four the fraction of decarboxylation that led to coupling. Perhaps the pyridine not only serves to "hold" the proton while the anion undergoes electron transfer and decarboxylation, but then "hands it back" to the decarboxylation intermediate (i.e., either the aryl radical or anion) before coupling can occur. We do not fully understand this chemistry yet, but it clearly could have profound implications for reducing decarboxylation-instigated coupling during coal liquefaction.

\section{TASK 4 - DATA INTEGRATION AND REPORTING}

An assessment of the role of carboxyl and hydroxyl functions, including the barium-exchanged forms, on coal liquefaction yields was prepared and included in Section III. A summary and interpretation was made of work on decarboxylation of activated benzoic acids, as described in Section IV. No additional work was done except routine report writing.

\section{PI.ANS FOR FIFTH QUARTER}

- Complete liquefaction expriments on moisturized coals.

- Prepare samples of $\mathrm{Ca}$ and $\mathrm{Na}$ exchanged coals.

- Complete preparation and characterization of modiifed polymers.

- Continue work on experiments and mechanisms of carboxyl group behavior. 


\section{REFERENCES}

Bamfield, P., Quam, P. M. Synthesis, 537, (1978).

Bishop and Ward, Fuel, 37, 191, (1958).

Chen, R. H., Kafafi, S. A., Stein, S. E., Am. Chem. Soc., 111, 1418, (1989).

Cohen, T., Schambach, J. Am. Chem. Soc., 92, 3189, (1970).

Fahr, A., Mailard, W. G., Stein, S. E., 21st Symposium International On Combustion: The Combustion Institute, 825, (1986).

Fahr, A., Stein, S. E., J. Phys. Chem., 92, 4951, (1988).

Friedel, C. Justus Liebigs Ann. Chem., 108, 122, (1958).

Gilbert, K. E., Gajewski, J. J., J. Org. Chem., 47, 4899, (1982).

Handbook of Chemistry and Physics, 57th Edition, Ed. Robert C. Weast, Chemical Rubber Publishing Co., Cleveland, Ohio, p. C.480, (1976a).

Handbook of Chemistry and Physics, 57th Edition, Ed. Robert C. Weast, Chemical Rubber Publishing Co., Cleveland, Ohio, p. C.-172, (1976b).

Herndon, W. C., J. Org. Chem., 46, 2119, (1981).

Herigel and Walker, Fuel, 63, 1215 (1986).

Hites, P. A., Biemann, K. J., Am. Chem. Soc., 94, 5772, (1972).

March, J., Advanced Organic Chemistry, 3rd Edition, John Wiley and Sons, New York, p 507, 562, 653, $842,928,(1985)$.

McMillen, D. F., Malhotra, R., Chang, S. J., Fleming, R. H., Ogier, W. C., Nigenda, S. E., Fuel, 66, 1611, (1987).

McMillen, D. F., unpublished work, (1985).

McMillen, D. F., Ogier, W. C., Ross, D. S., J. Org. Chem., 46, 3322, (1981).

Poutsma, M. L., "A Review of Thermolysis Studies of Model Compounds Relevant to Processing of Coal," Oak Ridge National Laboratory Report ORNL/TM-10637, (1987).

Serio, M. A., Hamblen, D. A., Markham, J. R., Solomon, P. R., Energy Fuels, 1, 138, (1987).

Serio, M. A., Solomon, P. R., G. V., Kroo, E., Bassilakis, R., Malhotra, R., McMillen, D.F., Arn. Chem. Soc. Div Fuel Chem. Prep., 35(1), 61,(1990).

Serio, M.A., Solomon, P.R., Kroo, E., Charpenay, S., and Bassilakis, R., "Fundamental Studies of Retrograde Reactions in Direct Liquefaction," Final Report for Contract No. DE-AC22-88PC88814 (Dec. 1991).

Schater, H., Fuel, 49, 197, (1970).

Schafer. H., Fuel, 51, 4, (1972). 
Siskin, M., private communication, (1991).

Solomon, P. R., Serio, M. A., Deshpande, G. V., Kroo, E., Energy Fuels, 4, 42, (1980).

Starinsic, M., Otake, Y., Walker, P.L., Jr., and Painter, P.C., Fuel, 63, 1002, (1984).

Stein, S. E., Griffith, L. L., Billmers, R., Chen, R. H., J. Org. Chem., 52, 1582, (1987).

Suuberg, E. M., Lee, D., Larsen, J. W., Fuel, 64, 1668, (1985). 

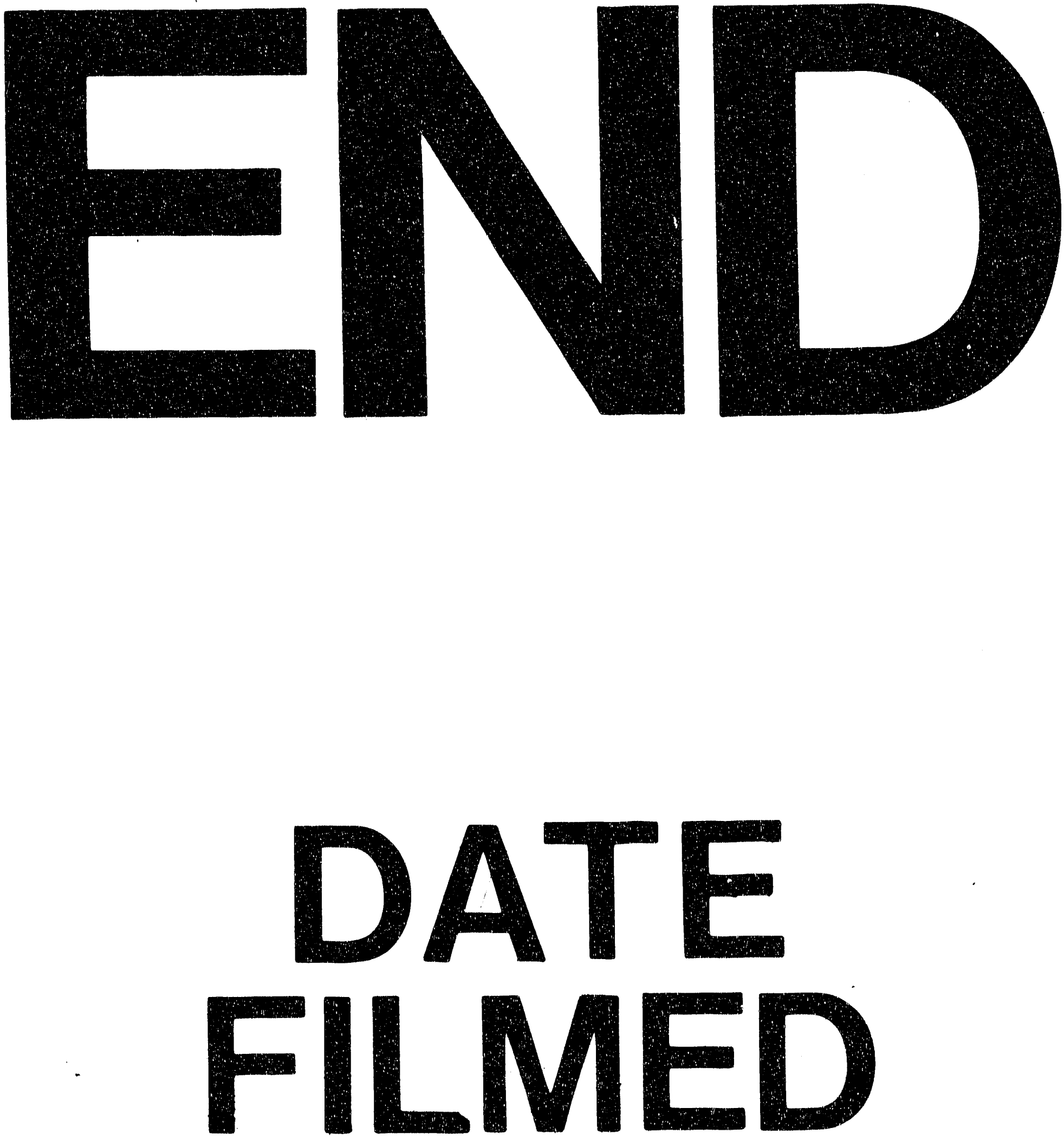

$\frac{1}{3}$

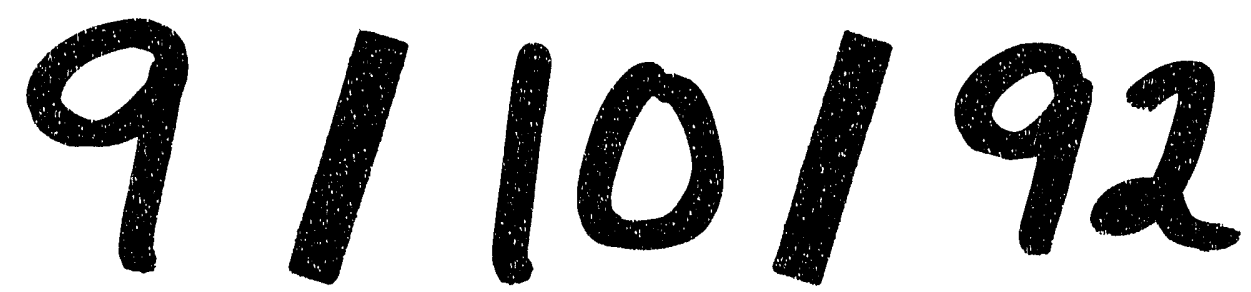


